\title{
Hochwirkungsgrad Hybridantrieb für nachhaltige Elektromobilität
}

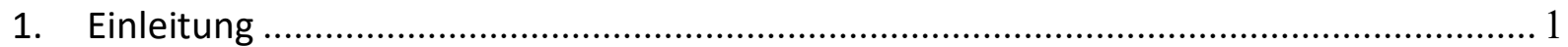

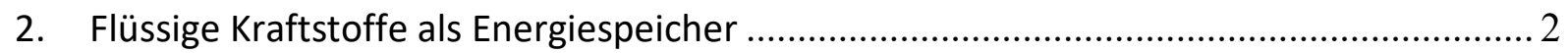

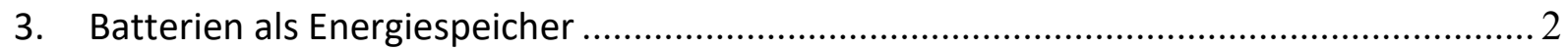

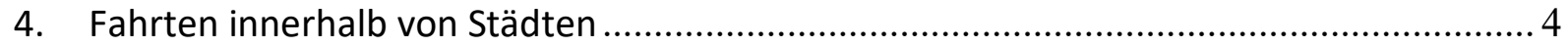

5. Langstreckenfahrten außerhalb von Ballungsräumen.................................................. 4

6. $\mathrm{CO}_{2}$ Emissionen konventioneller und batterieelektrischer Fahrzeuge............................. 7

7. Erzeugung der elektrischen Energie im Fahrzeug aus flüssigem Kraftstoff...................... 9

8. Kurzfristspeicherung der elektrischen Energie im Fahrzeug ......................................... 13

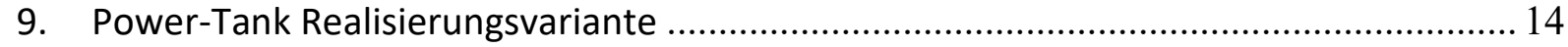

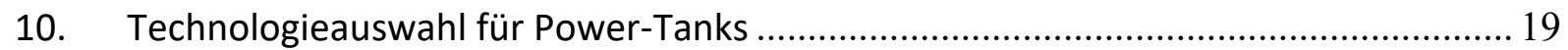

10.1. Allgemeine Überlegungen zur Technologieauswahl ............................................ 19

10.2. Speicherauswahl unter Berücksichtigung der Lastkollektive aus Fahrzyklen ........... 21

10.2.1. Realisierung eines Power-Tanks mit Batterien ................................................ 21

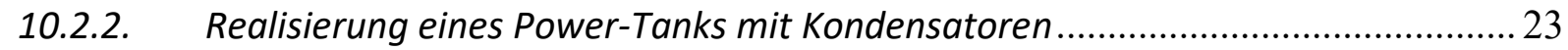

10.2.3. Realisierung eines Power-Tanks mit einem Schwungrad ..................................... 23

11. Simulation des elektrischen Antriebstranges im Artemis-Zyklus ............................... 24

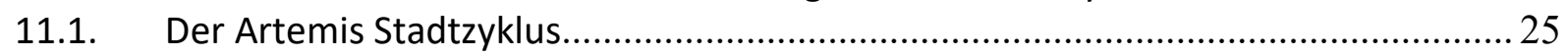

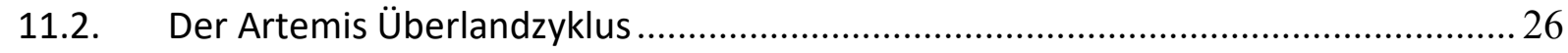

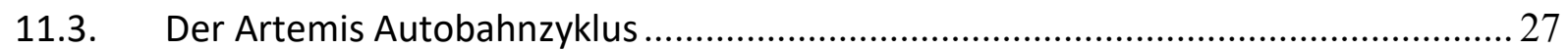

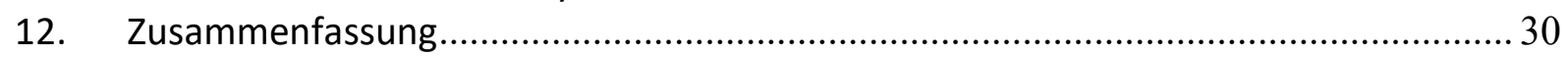

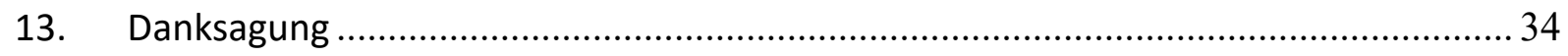

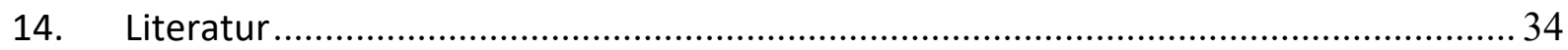

\section{Einleitung}

Die Einführung eines elektrischen Antriebes in Fahrzeugen ist eine technische Revolution, die vergleichbar mit der Umrüstung der Antriebsquelle in Fabriken im 20. Jahrhundert von Dampfmaschinen auf Elektroantrieb ist. Die Größe und die Komplexität einer Dampfmaschine - später ersetzt durch eine Verbrennungskraftmaschine - erlaubten es nicht, jeder Arbeitsmaschine wie z.B. Spinnmaschinen, Webstühlen, Schmiedehämmern, Walzstraßen, etc. eine individuelle Antriebsquelle zuzuordnen. Damit benötigte man einen Antriebsstrang, der die Antriebsleistung der Quelle über Getriebe, Wellen und Treibriemen auf viele Arbeitsmaschinen verteilt. Zufolge der langen Übertragungsstrecken und der damit verbundenen großen Anzahl an bewegten Teilen hat eine zentrale Kraftversorgung einen schlechten Wirkungsgrad, ist gefährlich (offene Riementriebe) und auf der Ebene der Arbeitsmaschine kaum regelbar.

Der Durchbruch wurde durch den Ersatz der zentralen Antriebsquelle durch viele dezentrale Elektromotoren erzielt. Damit ist die individuelle Steuerung und Regelung jeder Arbeitsmaschine einfach und kostengünstig machbar. Genau dieser Weg wird bei Fahrzeugen mit einem elektrifizierten Antriebsstrang begangen: Ein oder mehrere Elektromotoren treiben das Fahrzeug an. Getriebe und Wellen entfallen großteils, der Antrieb ist kostengünstig, robust und sehr gut regelbar.

Durch die Vorstellung des elektrisch betriebenen Lohner-Porsche Fahrzeuges $\left.\right|^{1}$, sind die herausragenden Vorteile eines elektrischen Fahrzeugantriebes seit Anfang des 20. Jahrhunderts bekannt. Trotzdem konnten sich Fahrzeuge mit elektrischem Antriebsstrang bis

\footnotetext{
$\left.\right|^{1}$ FAZ Seite T 4 / Dienstag, 30. Mai 2000, Nr. 125 Technik und Motor, access on 1.1.2020, https://web.archive.org/web/20080331224434/http://de.geocities.com/jayedelman/porsche.html
} 
heute nicht durchsetzen, weil die Versorgung mit elektrischer Energie für mehrere Stunden Fahrzeit und/oder ca. 800 km Reichweite und eine „Betankung“ in ein paar Minuten bis heute nur mangelhaft gelöst sind. Das war auch der Grund für den Siegeszug des Verbrennungsmotors für Fahrzeugantriebe, der zu Beginn des 20. Jahrhunderts Kopf an Kopf mit Elektrofahrzeugen begann.

Der elektrische Fahrzeugantrieb ist auch heute kein Problem, sondern - so wie vor über 100 Jahren - die Mitnahme beziehungsweise Speicherung und die rasche (Wieder-)Aufladung der elektrischen Energie für Fahrstrecken, die die Bevölkerung von Fahrzeugen mit Verbrennungsmotoren gewohnt ist.

\section{Flüssige Kraftstoffe als Energiespeicher}

Die Energiedichte üblicher Kraftstoffe für Fahrzeuge wie Benzin und Diesel ist ca. $12 \mathrm{kWh} / \mathrm{kg}$. Die hohe gravimetrische Energiedichte beruht zum Teil darauf, dass für eine vollständige Verbrennung von $1 \mathrm{~kg}$ Kraftstoff ungefähr 14,6 kg Umgebungsluft verwendet werden müssen. Da man die für die Verbrennung notwendige Luft aus der Umgebung beziehen kann, geht diese Masse nicht in die Energiedichtebetrachtung des Kraftstoffs ein. Damit sind bei für Menschen zumutbaren Temperatur- und Druckbedingungen flüssige Kohlenwasserstoffe für mobile Anwendungen unschlagbar, da neben der hohen gravimetrischen wie volumetrischen Energiedichte des Kraftstoffes das Tankgewicht weniger als $20 \%$ des Brennstoffes ausmacht. $\mathrm{Ob}$ ein Kraftstoff fossil basiert ist oder bei nahezu identischer Kraftstoffchemie synthetisch hergestellt wird, beeinflusst nicht die Funktion des damit betriebenen Verbrennungsmotors. Synthetische Kraftstoffe, hergestellt aus Solar- Wind- oder Geothermiestrom und „nachwachsendem Kohlenstoff", also nicht fossilem Kohlenstoff, reduzieren den $\mathrm{CO}_{2}$ Ausstoß eines Verbrennungsmotors signifikant $\left.\right|^{2}$, egal ob mit oder ohne elektrischen Antriebsstrang. Auf Grund der hohen Verluste im Herstellungsprozess von synthetischen Kraftstoffen, sind die Herstellkosten gegenüber fossil basierten Kraftstoffen leider immer noch zu hoch und damit deren Marktdurchdringung gering.

\section{Batterien als Energiespeicher}

Auf Batterien übertragen wäre es zur signifikanten Steigerung der Energiedichte ebenfalls sinnvoll, als Oxydationsmittel die Umgebungsluft zu verwenden. Dies ist bei den nicht wieder aufladbaren Zellen (Primärzellen) für beispielsweise Hörgeräte seit Jahren üblich und führt bei Zink-Luft Zellen auf eine Energiedichte von ca. $440 \mathrm{Wh} / \mathrm{kg}$ [2]. Wieder aufladbare Zellen (Sekundärzellen), welche die Umgebungsluft als Reaktionspartner verwenden, wie beispielsweise Lithium-Luft, Schwefel-Luft und Aluminium-Luft Batterien sind noch im Forschungsstadium [5] und [6]. Insbesondere konnte noch kein Weg gefunden werden, Batterien, die die Umgebungsluft als Reaktionspartner nutzen, in akzeptabler Zeit aufzuladen, ohne dass die Batterie signifikant an Kapazität verliert [5]. Gegenüber der heute gebräuchlichen LithiumIonen Batterien könnten in der Entwicklung befindliche wieder aufladbare Aluminium-lonen Zellen $400 \mathrm{Wh} / \mathrm{kg}$ [3] und Aluminium-Schwefel Zellen $1000 \mathrm{Wh} / \mathrm{kg}$ [4] erreichen.

Nur dort, wo zufolge der geringen Geschwindigkeit der Fahrzeuge der Energieaufwand zur Zurücklegung einer Wegstrecke gering ist und man insbesondere auf minimale Feinstaubbelastung und NOx Emissionen Wert legen muss, wie beispielsweise in Städten und Ballungsräumen, ist der Einsatz von batterieelektrischen Fahrzeugen sinnvoll. Für eine angestrebte Reichweite von gut $100 \mathrm{~km}$, erlaubt die geringe Durchschnittsgeschwindigkeit von 20 bis

\footnotetext{
$1^{2}$ Diese Kraftstoffe werden synthetisch unter Zuhilfenahme von Solar- oder Windenergie und Kohlenstoff mit geringer $\mathrm{CO}_{2}$ Belastung für die Umwelt hergestellt.
} 
$25 \mathrm{~km} / \mathrm{h}$ in Ballungsräumen den Energieinhalt der Fahrzeugbatterie auf ca. $25 \mathrm{kWh}$ zu begrenzen. Die langsame Entladezeit von 4 bis 5 Stunden gestattet den Einsatz einer Batterie mit besonders hoher gravimetrischer Energiedichte (,Hochenergiebatterie mit ca. $260 \mathrm{Wh} / \mathrm{kg}$ auf Zellebene" ${ }^{3}{ }^{3}$ ), die in einem Batteriepack mit 110 bis $120 \mathrm{~kg}$ mit heute verfügbaren LithiumIonenzellen [7] aufgebaut werden kann. Dieser Weg spart Kosten, Gewicht, Platz und man kann auf die Batteriekühlung nahezu verzichten, da bei mehrstündiger Entladung die Verlustleistung in der Batterie gering ist. Trotzdem haben Hochenergiebatterien immer noch um gut einen Faktor 40 geringere gravimetrische Energiedichten als flüssige Kraftstoffe.

Auch in Städten und Ballungsräumen wird erwartet, dass ein Fahrzeug exzellente Beschleunigung bietet und zur Vermeidung von Bremsenstaub möglichst jede Bremsung nahezu ausschließlich über elektrische Bremsenergierückgewinnung (Rekuperation) leistet. Eine Hochenergiebatterie mit „nur" 25 kWh Energieinhalt würde bei der hohen vom Fahrzeug verlangten Dynamik und der damit verbundenen hohen Leistung des elektrischen Antriebsstranges die Batterie unzulässig belasten und folglich die Lebensdauer verringern. Eine Hochleistungsbatterie [8] - [10] mit 25 kWh hätte kein Verlustleistungsproblem mit der hohen Fahrzeugdynamik, die um den Faktor 2 bis 4 geringere gravimetrische Energiedichte $\mid{ }^{4}$ verbietet aber aus Kosten- und Gewichtsgründen den Einsatz dieses Batterietyps. Der Widerspruch „Einsatz einer Hochenergiebatterie zufolge mehrstündiger Entladung" gegenüber "kurzfristige Belastung der Hochenergiebatterie mit hoher Leistung durch dynamische Fahrweise" lässt sich durch die Verwendung eines zusätzlichen Hochleistungsenergiespeichers lösen.

Der in Kapitel 9 und 10 näher ausgeführte Hochleistungsenergiespeicher, im Folgenden als „Power-Tank“ bezeichnet, benötigt nur einen geringen Energieinhalt aber hohe Leistung und ermöglicht in batterieelektrischen Fahrzeugen leichte und platzsparende Hochenergiebatterien einzusetzen. Das energieoptimierte Batteriemodul hat bei gleichem Energieinhalt ein deutlich geringeres Gewicht als die heute üblichen Batteriemodule mit höherer Leistungsdichte, da diese einen Kompromiss zwischen Energiedichte, Leistungsdichte und Kühlungsaufwand der Batterie eingehen müssen. Um Schädigungen zu vermeiden, dürfen Hochenergiebatterien nur langsam, typischerweise in zwei bis vier Stunden, aufgeladen werden. Das muss kein Nachteil sein, da damit die Ladeinfrastruktur mit der heute in einem Haushalt verfügbaren Anschlussleistung zu bewältigen ist.

Wenn große Strecken über Land mit hoher Geschwindigkeit zurückzulegen sind, machen batterieelektrische Fahrzeuge hingegen keinen Sinn, denn die Antriebsleistung wächst mit der dritten Potenz der Geschwindigkeit und dieser Fahrwiderstand dominiert bei heutigen Fahrzeugen bereits ab ca. $80 \mathrm{~km} / \mathrm{h}$. Damit braucht man, um Fahrstrecken von 300 bis $400 \mathrm{~km}$ mit Autobahngeschwindigkeit zurückzulegen, sehr energiereiche Batteriepacks mit gut $600 \mathrm{~kg}$ Eigengewicht [11] - [13]. Die große Batterie erhöht das Fahrzeuggewicht signifikant und damit auch den Energiebedarf des Fahrzeuges; das ist eine Spirale in die falsche Richtung. Die Sicherheit von Batterien mit großem Energieinhalt, der heute ausschließlich mittels LithiumIonen Technologie realisierbar ist, lässt sich nur bedingt sicherstellen, weder bei allen möglichen Batteriedefekten noch bei schweren Unfällen. Im Brandfall ist das Löschen der

\footnotetext{
| ${ }^{3}$ Man kann auf die Zellenchemie heute üblicher Laptop- und Mobiltelefonzellen zurückgreifen.

$1{ }^{4}$ Hochleistungs-Lithium Batterien mit Lithiumtitanspinell ( $\mathrm{Li}_{4} \mathrm{Ti}_{5} \mathrm{O}_{12}$ ) Anode haben eine Energiedichte von 30 bis 110 Wh/kg und einige 10.000 Lade-Entladezyklen @ 10 C [36], Ultra High Power NMC Zellen zu 140 Wh/kg und bis zu 4.000 Lade-Entladezyklen @ 4 C, Hochenergie-Batterien von ca. 260 Wh/kg und einige 1000 LadeEntladezyklen@ 0,5 C [7] bis [10].
} 
Batterie nahezu unmöglich und es entweichen aus der brennenden Batterie für die Umwelt und den Menschen giftige Gase in großer Menge $\left.\right|^{5}$.

Um - so wie heute gefordert - beliebig lange Strecken mit einem batterieelektrischen Elektrofahrzeug zurücklegen zu können, benötigt man eine Batterie mit großem Energieinhalt. Das Laden dieser Batterien setzt eine in jedem Land aufzubauende und mit gewaltigen Kosten verbundene, flächendeckende Schnelllade-Infrastruktur voraus. Die damit erreichbare kurze Nachladezeit für ca. 60 \% der Batterieenergie in 15 Minuten ist immer noch lange, verglichen mit der heute typischen Nachtankzeit mit flüssigem Kraftstoff von 3 bis 5 Minuten und fordert hohe Netzanschlussleistungen jenseits der $150 \mathrm{~kW}$ pro Ladestation. Die vom Kunden geforderte rasche Nachladezeit der Batterie verhindert den Einsatz von Zellen mit hoher Energiedichte und verlangt zusätzlich einen großen Kühlaufwand der Zellen, viel mehr als man für den Fahrbetrieb benötigt, denn es ist unmöglich, im Fahrbetrieb in 15 Minute $60 \%$ der Batterieenergie zu verbrauchen. Damit sind die im Fahrzeug verbauten Zellen eher Zellen, die auf hohe Leistungsdichte statt auf hohe Energiedichte optimiert sind.

Zusammenfassend kann man festhalten, dass nicht alles, was technisch machbar ist, auch sinnvoll ist. Das Ziel muss sein, eine nachhaltige Mobilität bei kleinstmöglicher $\mathrm{CO}_{2}$ Belastung darzustellen. Die Kapitel 6 bis 10 zeigen einen Weg auf, wie man bei einer fairen „Well-toWheel" oder noch besser "Cradle-to-grave " $\left.\right|^{6}$ Betrachtung gegenüber batterieelektrischen Fahrzeugen mit großen Batterien, die über eine Schnellladeinfrastruktur geladen werden, durch eine Senkung der Emissionen und des $\mathrm{CO}_{2}$ Ausstoßes nachhaltige Mobilität realisieren kann.

\section{Fahrten innerhalb von Städten}

Die vielerorts hohe und auf den Verkehr zurückzuführende Partikel- und gasförmige Schadstoffbelastung üben großen Druck auf die Politik aus, im städtischen Bereich nur mehr Fahrzeuge zuzulassen, deren Energiespeicher und Antriebsstrang während der Fahrt keine Schadstoffe freisetzen, also beispielsweise batterieelektrische Fahrzeuge oder mit Wasserstoff betriebene Polymermembran (PEM) Brennstoffzellenfahrzeuge. Beide Fahrzeugkategorien werden am Markt angeboten. Für Wasserstoffbrennstoffzellenfahrzeuge fehlt ein flächendeckendes Tankstellennetz, womit für den städtischen Verkehr kurz- bis mittelfristig nur batterieelektrische Fahrzeuge oder Hybridfahrzeuge, die innerstädtisch rein elektrisch fahren, in Frage kommen.

\section{Langstreckenfahrten außerhalb von Ballungsräumen}

Der Betrieb eines Fahrzeuges über größere Distanzen außerhalb der städtischen Ballungsräume stellt andere Anforderungen an den elektrischen Antriebsstrang und an dessen Energiespeicher als eine innerstädtische Fahrt. Nicht mehr der Ort der Schadstofffreisetzung ist wichtig, sondern der gesamte $\mathrm{CO}_{2}$, Partikel- und gasförmige Schadstoffausstoß muss minimiert werden, möglichst in einer „Well-to-Wheel“ oder noch präziser "Cradle-toGrave" Betrachtung. Es ist unerheblich, ob dieser Ausstoß durch das Fahrzeug erfolgt oder durch ein Kraftwerk, das die Elektrizität zum Nachladen der Fahrzeugbatterie bereitstellt oder

\footnotetext{
$\mathrm{I}^{5}$ Im Falle des Versagens von Lithium-Ionen-Batterien entstehen je nach Zusammensetzung der Batterien Fluorwasserstoff und Phosphorsäure sowie weitere giftige und kanzerogene Stoffe. Je nach Zusammensetzung werden Schwermetalle in Form von Nickel- und Cobaltoxiden sowie Graphit und ca. 150 I gasförmiger Fluorwasserstoff (HF) pro kWh Batterieenergie freigesetzt. Eine 18650 2,2 Ah Zelle speichert 8,7 Wh elektrische Energie, setzt eine thermische Energie von $100 \mathrm{Wh}$ und 11 I Gasmenge frei. Bei einer 20 kWh BEV Batterie ist die chemisch gespeicherte Energie das 7 bis 11 Fache und sie setzt 12500 I Gasmenge frei [52].

${ }^{6}$ Auch als Lebenszyklusanalyse oder Life Cycle Assessment bezeichnet
} 
durch eine Raffinerie, die den Wasserstoff für die Betankung des Brennstoffzellenfahrzeuges produziert.

Die Automobilindustrie hat erkannt, dass es kontraproduktiv zu den Anstrengungen ist, die Anzahl an Fahrzeugen des nicht öffentlichen Verkehrs zu reduzieren, wenn man zwei Fahrzeugtypen anbietet: ein BEV mit kleiner Batterie für Städte und Ballungsräume und ein Fahrzeug für längere Strecken bei höheren Fahrgeschwindigkeiten. Das Ziel ist daher, EIN Fahrzeug anzubieten, das sowohl als BEV in Ballungsräumen emissionsfrei arbeitet als auch außerhalb lange Strecken bei hoher Geschwindigkeit zurücklegen und rasch „nachgetankt" werden kann.

Die Automobilindustrie bietet gegenwärtig zwei Fahrzeugvarianten an, die beide den Anspruch erheben, innerstädtisch wie über Land gegenüber heute verfügbaren konventionellen Fahrzeugen mit $\mathrm{Vkm}$, die $\mathrm{CO}_{2}$ Emissionen signifikant zu verringern, leistbar und soziologisch verträglich zu sein.

Fahrzeugtype A) Die Proponenten von BEV mit großen Batterien verdrängen,

- dass aus globaler Sicht der Strom zum Nachladen noch für viele Jahre mehr $\mathrm{CO}_{2}$ hervorrufen wird, als Fahrzeuge mit dem in diesem Papier vorgestellten Hybridkonzept,

- dass die Risiken und Bedenken zufolge der neuen Rohstoffabhängigkeiten (Lithium, Kobalt, Nickel, Mangan, ...) für die Produktion von Lithium-lonen Batterien ernst zu nehmen sind,

- dass die in Kapitel 3 adressierten Probleme der Schnellladung von großen Batterien hohe Investitionen in den Netzausbau erfordern und damit lange dauern wird und

- dass gewisse Fahraufgaben, für die grundsätzlich viel Energie notwendig ist und die der Kunde von konventionellen Pkw als beherrschbar kennt, nicht erfüllt werden können. Nicht erfüllt bedeutet, dass die Reichweite oder die Nutzungszeit des BEV bis zum nächsten Nachladen unakzeptabel kurz wird oder der Fahrer gezwungen ist, die Fahrgeschwindigkeit unangemessen zu verringern. Beispiele für energieaufwändige Fahraufgaben sind, Dachtransporte mit Boxen oder Fahrrädern auf der Autobahn, Winterbetrieb bei großer Kälte und höherer Geschwindigkeit oder das Ziehen von Booten und Wohnwagen.

Fahrzeugtype B) Hybrid und Plug-in Hybrid Fahrzeuge kombinieren eine kleine bis mittelgroße Batterie mit einer Vkm, die über ein vielstufiges Automatikgetriebe (auch) mit den Antriebsrädern verbunden ist.

- Mit diesem Konzept vermeidet man die Probleme im Zusammenhang mit Schnellladung von BEV und kann das bestehende Tankstellensystem zur Abdeckung der Reichweite nutzen.

- Da die Batterie relativ wenig Kapazität hat, kann die erwartete Fahrzeugbeschleunigung nicht ausschließlich mit elektrischer Energie aus der Batterie erfolgen. Die Vkm muss ebenfalls Beschleunigungsleistung liefern und über einen großen Last- und Drehzahlbereich betreibbar sein. Damit ist trotz vielstufigem Automatikgetriebes zur Lastpunktverschiebung der Wirkungsgrad der Vkm in großen Bereichen des Kennfeldes weit weg von optimal.

- Das Resultat ist eine vom Hersteller ermittelte fahrzeugspezifische $\mathrm{CO}_{2}$ Emissionsangabe, die realitätsfremd ist, da beim Testlauf die Vkm möglichst wenig eingesetzt wird und die beim Test verbrauchte elektrischer Energie mit Null $\mathbf{g} \mathrm{CO}_{2}$ Emissionen in die 
Berechnung eingeht. In Kundenhand sind damit der Kraftstoffverbrauch und damit auch die $\mathrm{CO}_{2}$ Emissionen viel höher, als vom Hersteller in den Papieren festgehalten.

Der Hybridansatz der Automobilindustrie war die Motivation durch die Einführung eines „Fuel-Converters" statt der Vkm und eines „Power-Tanks“ statt der kleinen bis mittelgroßen Batterie zu einer Lösung zu kommen, die simulationsbasiert gegenüber konventionellen Fahrzeugen mit Vkm signifikant $\mathrm{CO}_{2}$ einspart und gleichzeig die weiter oben erwähnten Probleme der handelsüblichen BEV und Hybridfahrzeuge vermeidet.

Gegenüber Stadtfahrten mit Durchschnittsgeschwindigkeiten von 20 bis $25 \mathrm{~km} / \mathrm{h}$ steigern Langstreckenfahrten auf Freilandstraßen und Autobahnen die Geschwindigkeit auf ein Vielfaches. Damit steigt auch die Antriebsleistung zufolge des mit der dritten Potenz der Geschwindigkeit $v$ wachsenden Luftwiderstandes. Die folgende Tabelle 1 zeigt, welche Energie man benötigt, um bei Konstantfahrt auf der Autobahn eine Strecke von $400 \mathrm{~km}$ ohne Zusatzverbrauch für Nebenaggregate (typisch $2 \mathrm{~kW}$ ) zurückzulegen. Bergiges Gelände, ungleichmäßige Fahrweise und oftmaliges starkes Beschleunigen erhöhen trotz Bremsenergierückgewinnung den genannten Energiebedarf.

Tabelle 1 Antriebsleistung, Energieverbrauch und Fahrzeit eines Fahrzeuges gemäß Abb. 1 bei Konstantfahrt über eine Distanz von 400 km und ohne Zusatzverbrauch für Nebenaggregate bei verschiedenen Geschwindigkeiten.

\begin{tabular}{|c|c|c|c|c|c|}
\hline \multirow{2}{*}{$\begin{array}{c}\text { Geschwin- } \\
\text { digkeit }\end{array}$} & $\begin{array}{c}\text { Fahrzeit für } \\
400 \mathrm{~km}\end{array}$ & \multicolumn{2}{|c|}{ Antriebsleistung } & \multicolumn{2}{|c|}{$\begin{array}{c}\text { Energieverbrauch des } \\
\text { Antriebstranges abhängig } \\
\text { vom Wirkungsgrad } \eta\end{array}$} \\
\cline { 3 - 6 } & & $\begin{array}{c}\text { mechanisch } \\
\text { am Rad }\end{array}$ & $\begin{array}{c}\text { elektrisch aus } \\
\text { dem Speicher }\end{array}$ & $\eta=100 \%$ & $\eta=$ realistisch \\
\hline $80 \mathrm{~km} / \mathrm{h}$ & $5 \mathrm{~h}$ & $8,1 \mathrm{~kW}$ & $11,0 \mathrm{~kW}$ & $40,5 \mathrm{kWh}$ & $55,0 \mathrm{kWh}$ \\
\hline $100 \mathrm{~km} / \mathrm{h}$ & $4 \mathrm{~h}$ & $12,9 \mathrm{~kW}$ & $17,1 \mathrm{~kW}$ & $51,6 \mathrm{kWh}$ & $68,4 \mathrm{kWh}$ \\
\hline $130 \mathrm{~km} / \mathrm{h}$ & gut $3 \mathrm{~h}$ & $23,6 \mathrm{~kW}$ & $30,2 \mathrm{~kW}$ & $72,6 \mathrm{kWh}$ & $92,9 \mathrm{kWh}$ \\
\hline $150 \mathrm{~km} / \mathrm{h}$ & $23 / 4 \mathrm{~h}$ & $33,7 \mathrm{~kW}$ & $42,3 \mathrm{~kW}$ & $89,9 \mathrm{kWh}$ & $112,8 \mathrm{kWh}$ \\
\hline $180 \mathrm{~km} / \mathrm{h}$ & $21 / 4 \mathrm{~h}$ & $54,0 \mathrm{~kW}$ & $66,3 \mathrm{~kW}$ & $120,0 \mathrm{kWh}$ & $147,3 \mathrm{kWh}$ \\
\hline
\end{tabular}

100 kWh Energie in Batterien gespeichert bedeuten ca. 80 - 90 kWh effektiv nutzbare Energiemenge und gut $600 \mathrm{~kg}$ Batteriegewicht [11] - [14]. Diese zusätzliche Fahrzeugmasse muss durch konstruktive Maßnahmen im Rahmen, in den Radaufhängungen und in der Karosserie Rechnung getragen werden, womit das Fahrzeuggewicht weiter zunimmt. Damit stellt sich die Frage, ob es nicht zur Gewichtsreduktion des Fahrzeuges sinnvoll wäre, die elektrische Energie an Bord aus flüssigem Kraftstoff bereitzustellen, statt aus schweren Batterien mit hoher Kapazität zu beziehen. Allerdings macht die Energiekonversion im Fahrzeug nur dann Sinn, wenn das Fahrzeuggewicht dadurch sinkt und die Bereitstellung der elektrischen Energie mit hohem Wirkungsgrad, also mit vergleichbarer oder geringerer $\mathrm{CO}_{2}$ - und Schadstoffbelastung bewerkstelligt werden kann als die $\mathrm{CO}_{2}$ - und Schadstoffbelastung zur Bereitstellung der elektrisch nachzuladenden Energie aus dem Netz verursachen würde. Ein geringes Fahrzeuggewicht hilft zusätzlich, den Energieverbrauch des Fahrzeuges und im Crash-Fall die Unfallfolgen für den Unfallgegner zu verringern. 


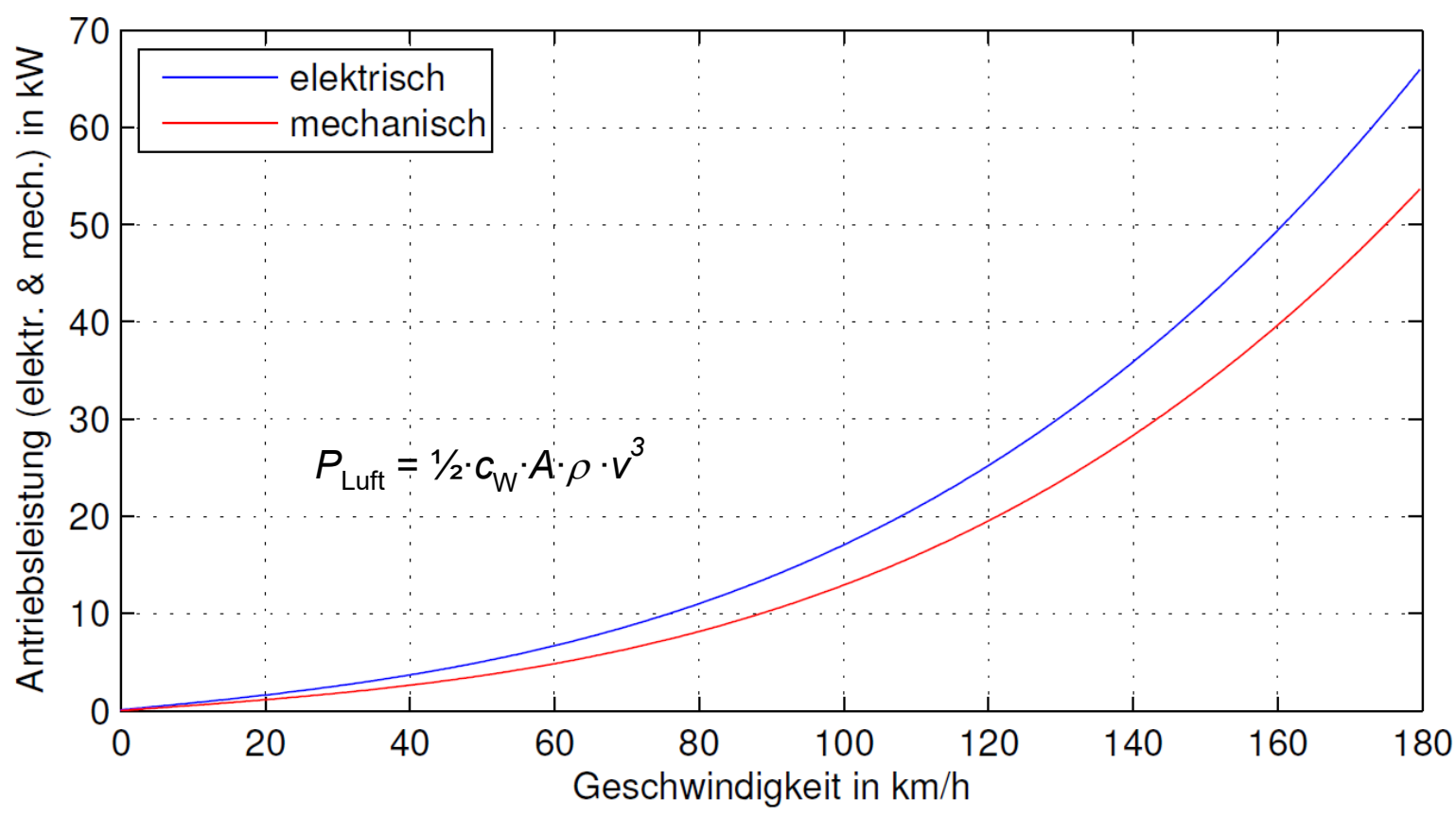

Abb. 1: Leistungsbedarf $P_{\text {Luft }}$ eines Mittelklassefahrzeuges mit einem Rollwiderstandsbeiwert $\mu=0,013$, der Luftdichte $\rho=1,225$ und einem Luftwiderstand $c_{W} A=0,60$ aus [1]. Die gezeigte elektrische Antriebsleistung berücksichtigt die Wirkungsgradkette des Antriebsstranges aber nicht die elektrische Antriebsleistung für die Nebenaggregate.

\section{6. $\mathrm{CO}_{2}$ Emissionen konventioneller und batterieelektrischer Fahrzeuge}

Etwa die Hälfte des Stromes wird heute in Europa aus fossilen Quellen, insbesondere aus Kohle und Erdgas gewonnen [40] und [50]. Aus globaler Sicht wird Strom im Durchschnitt mit $518 \mathrm{~g} \mathrm{CO}_{2} / \mathrm{kWh}$ bereitgestellt [22]. Auch Wasserstoff wird zur Zeit vorwiegend über Steamreforming aus Erdgas generiert und dieser Zustand wird sich global betrachtet leider nur langsam ändern. Der durchschnittliche elektrische Wirkungsgrad fossiler Kraftwerke zur Stromerzeugung, die großtechnisch immer Gas- und/oder Dampfturbinen (GuD) einsetzen, liegt weltweit bei ca. $33 \%$ [20]. Deutsche Kraftwerke erreichen im Mittel derzeit ca. $38 \%$ Wirkungsgrad und die im letzten Jahrzehnt ans Netz gegangenen neuen Kohlekraftwerke liegen zwischen 40 und $45 \%$ [20]. Neue und mit dem Brennstoff Erdgas betriebene GuDKraftwerke erreichen bis zu $64 \%$ Wirkungsgrad [20] \& [21].

Abb. 2 zeigt einen Vergleich der Lebenszyklus-Treibhausgasemissionen in $\mathrm{CO}_{2}$-eq von Fahrzeugen mit Verbrennungskraftmaschinen (ICE), von Hybrid-(HEV), von Plug-in-Hybrid (PHEV), von batterieelektrischen (BEV) und von Brennstoffzellen-Fahrzeugen (FCEV) [22], wenn die Kraftstoffe fossil sind, für die Aufladung der Batterie der Mittelwert der $\mathrm{CO}_{2}$ Emissionen einer globalen Elektrizitätserzeugung von $518 \mathrm{gCO}_{2} / \mathrm{kWh}$ angenommen wird und man Wasserstoff über "Steam-Reforming“ herstellt. Man erkennt, dass ein mit fossilen Kraftstoffen betriebener Kleinwagen (ICE-small) vergleichbare $\mathrm{CO}_{2}$ Emissionen aufweist wie ein großes Elektrofahrzeug (BEV) und wie ein mittelgroßes Brennstoffzellenfahrzeug (FCEV).

Um das Ziel, den globalen $\mathrm{CO}_{2}$ Footprint des Verkehrs in absehbarer Zeit signifikant abzusenken, sind Elektrofahrzeuge offensichtlich schlecht geeignet, da der Ersatz von fossilen Energieträgern zur Stromerzeugung durch $\mathrm{CO}_{2}$ arme Energieträger ein langwieriger und teurer Prozess ist. 


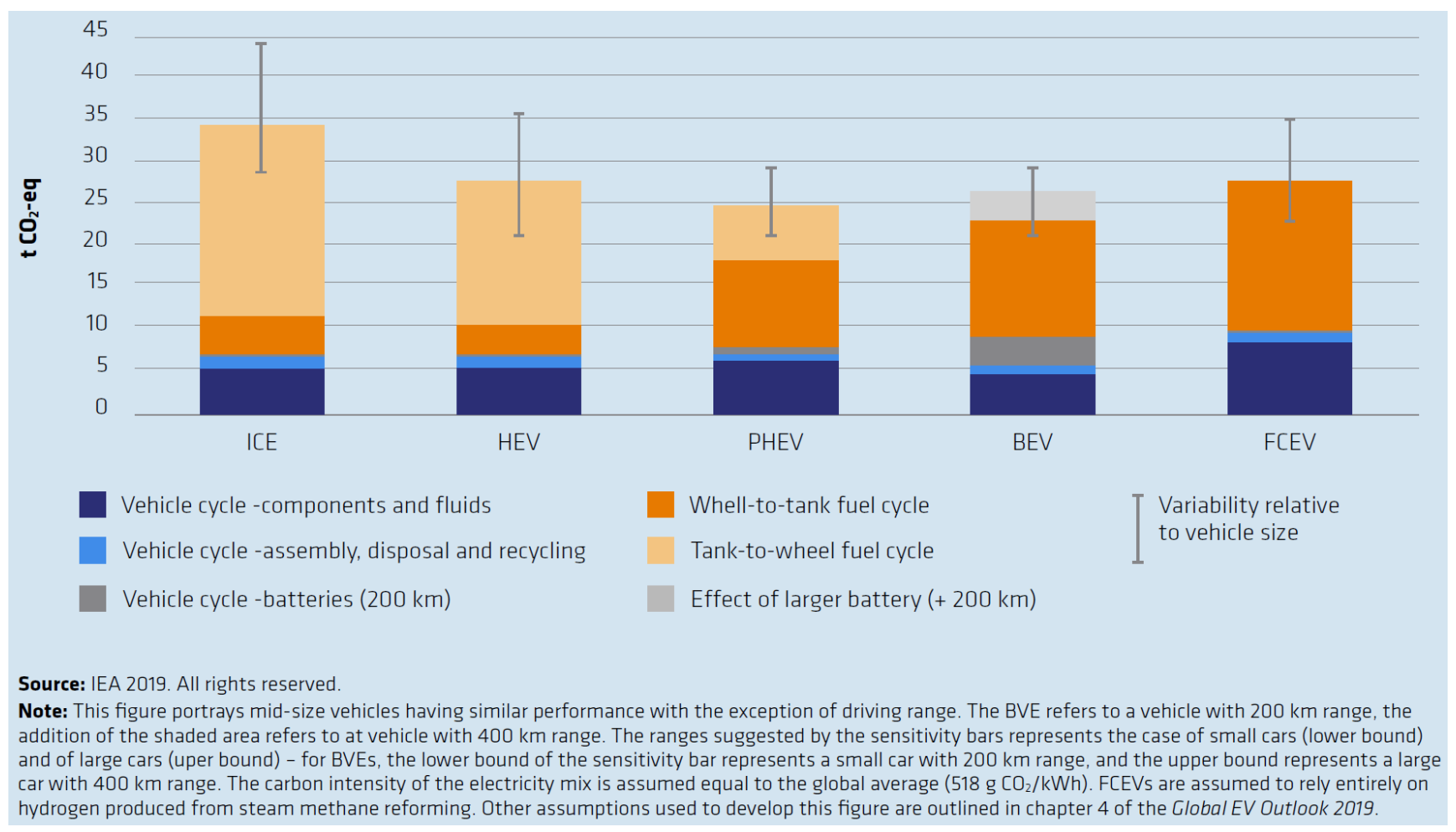

Abb. 2: Vergleich der Lebenszyklus-Treibhausgasemissionen eines Mittelklasse Pkw nach Antriebsstrang, 2019 [22].

Wesentlich rascher ließe sich das Ziel einer $\mathrm{CO}_{2}$ Emissionssenkung dadurch erreichen, dass der Wirkungsgrad von Fahrzeugen, die mit Benzin oder Dieselkraftstoff betrieben werden, signifikant gesteigert wird. Diese Maßnahme soll nicht ein Ersatz für die Vermeidung fossiler Energie zur Stromerzeugung sein, sondern eine zusätzliche Brückentechnologie zur Vermeidung von $\mathrm{CO}_{2}$ Emissionen, bis global "grüner" Strom und damit auch „grüner" Wasserstoff die Regel und nicht die Ausnahme ist.

Das mit Abstand größte Potenzial zur Senkung der $\mathrm{CO}_{2}$ Emissionen von Vkm liegt in der Wahl des Arbeitspunktes, denn im Stadtverkehr haben Pkw-Dieselmotoren einen Wirkungsgrad von ca. $20 \%$ und Pkw-Ottomotoren von 10 bis $15 \%$, hingegen im Bestpunkt bei Pkw-Dieselmotoren ca. $42 \%$ und bei Pkw-Ottomotoren ca. $37 \%$ [23]. Das bedeutet, dass eine Lastpunkverschiebung der $\mathrm{Vkm}$ in den Bestpunkt die $\mathrm{CO}_{2}$ Emissionen mehr als halbieren könnte, denn der Verkehr wird sich weltweit immer mehr in Städten und Ballungsräumen abspielen. Zur Zeit leben bereits mehr als 50 \% der Weltbevölkerung in Ballungsräumen, für 2050 geht [51] von $70 \%$ aus.

Die optimale Lastpunktverschiebung bei einer Vkm bedeutet deren Betrieb ausschließlich im Bestpunkt, also bei einer bestimmten Drehzahl und bei einer bestimmten Last. Leider kann man ein Straßenfahrzeug nicht mit konstanter Leistung betreiben. Ergo benötigt man ein Elektro-Hybridkonzept, das den rein elektrischen Antriebsstrang aus einem elektrischen Energiespeicher versorgt und die Vkm stellt mittels eines mit der Vkm verbundenen Generators sicher, dass der elektrische Energiespeicher nicht leer wird. Unter den im nächsten Kapitel gezeigten Voraussetzungen hat ein mit einem Verbrennungsmotor betriebenes ElektroHybridfahrzeug noch für lange Zeit einen vergleichbaren bis geringeren $\mathrm{CO}_{2}$ - und Schadstoffausstoß als ein batterieelektrisches Fahrzeug, das unter Berücksichtigung der länderspezifi$\underline{\text { schen } \mathrm{CO}_{2}}$ Belastung der elektrischen Energiebereitstellung aus dem Netz geladen wird. 
Weitere Varianten, um aus einem im Fahrzeug mitgeführten Kraftstoff mit hoher Energiedichte Elektrizität für den Betrieb des elektrischen Antriebsstranges eines Fahrzeuges bereitzustellen, werden im nächsten Kapitel diskutiert.

\section{Erzeugung der elektrischen Energie im Fahrzeug aus flüssigem Kraftstoff}

Als Energiekonverter für Elektrizität aus flüssigen Kohlenwasserstoffen eignen sich Festoxidbrennstoffzellen (Solid Oxide Fuel Cells, SOFC) oder Verbrennungsmotoren mit einem Generator. Gegenwärtig verfügbare SOFC arbeiten zwischen 750 und $1000{ }^{\circ} \mathrm{C}$ und haben bis zu $65 \%$ ([26], [27]) Konversionswirkungsgrad. Der Aufwärm- und Abkühlvorgang einer SOFC muss über viele Minuten bis Stunden erfolgen, damit der Keramik-Metall Stack die hohe mechanische Belastung der Temperaturänderung unbeschadet übersteht. Trotzdem hält ein Stack nur ein paar hundert Aufheizzyklen aus. In einem stationären Betrieb, wie etwa zur Strom- und Wärmegewinnung im Haushalt ist diese Betriebseinschränkung nicht störend, für Fahrzeuganwendungen, die hohe dynamische Anforderungen an die Energiequelle stellen, sind heutige SOFC Stacks ungeeignet.

Polymermembran (PEM) Brennstoffzellen wären grundsätzlich als Energiekonverter gut geeignet. Allerdings benötigen PEM-Zellen als Energieträger hochreinen Wasserstoff und dieser wird, wie in Kapitel 4 ausgeführt, auch in absehbarer Zeit nicht flächendeckend und vorwiegend nur aus fossilen Quellen hergestellt, verfügbar sein.

Somit bleiben nur mit Generatoren gekoppelte Gasmaschinen, um flüssige Kraftstoffe in elektrische Energie umzuwandeln. Gasmaschinen nutzen einen thermischen Kreisprozess (Carnot-Prozess), über den die in einem Gas gespeicherte Wärmeenergie in mechanische Arbeit umgewandelt wird. Der ideale Wirkungsgrad $\eta_{\mathrm{i}}=1-\left(T_{\mathrm{A}} / T_{\mathrm{V}}\right)=1-\left(T_{\min } / T_{\max }\right)$ eines verlustlosen (idealen) Kreisprozesses wird gemäß vorstehender Formel nur vom Temperaturunterschied zwischen der (Verbrennungs)temperatur $T_{V}$ des Gases im Arbeitsraum und der Austrittstemperatur $T_{\mathrm{A}}$ aus dem Arbeitsraum bestimmt. Die grundsätzlichen Überlegungen gelten auch für reale und verlustbehaftete Gasmaschinen. Zur Optimierung des Wirkungsgrades sollte ohne wesentliche Vergrößerung der von der Gasmaschine abgegebenen Verlustwärme die Temperatur $T_{\max }$ im Arbeitsraum maximiert und die Austrittstemperatur $T_{\mathrm{A}}$ aus dem Arbeitsraum minimiert werden.

Die intermittierende Verbrennung eines Viertakt Hubkolbenmotors erlaubt eine sehr hohe Flammentemperatur im Brennraum (ca. 2200 bis $2600{ }^{\circ} \mathrm{C}$ [15] - [18]), da diese nur ca. $5 \%$ der Zykluszeit einwirkt ( $30^{\circ}$ Kurbelwinkel (KW) bezogen auf $720^{\circ} \mathrm{KW}$ des Arbeitszyklus). Zufolge der thermischen Trägheit und einer angemessenen Bauteilekühlung erwärmen sich trotz der hohen Verbrennungstemperatur die für die Umwandlung der thermischen Energie in mechanische Arbeit notwendigen Bauteile (Zylinder, Kolben, Ventile) auf eine über einen Arbeitszyklus $\left(720^{\circ} \mathrm{KW}\right)$ gemittelte Temperatur, die nur bei wenigen $100^{\circ} \mathrm{Cliegt}$. Drauf beruht der grundsätzlich höhere Wirkungsgrad einer Gasmaschine mit intermittierender Verbrennung $(\mathrm{Vkm})\left(\boldsymbol{\eta}_{\mathrm{i}}=1-\left(T_{\mathrm{A}} / T_{\mathrm{V}}\right)=1-(1100 \mathrm{~K} / 2900 \mathrm{~K})=\mathbf{0 , 6 2}\right)$ gegenüber einer mit kontinuierlicher Verbrennung (Gasturbine).

Die mit kontinuierlicher Verbrennung arbeitende Gasturbine erlaubt eine Turbineneintrittstemperatur von maximal 1200 bis $1600{ }^{\circ} \mathrm{C}$ ([19] - [21]), da die Turbinenschaufeln ungefähr die gleiche Temperatur wie die Verbrennungsgase annehmen und derzeit kein Werkstoff existiert, der eine höhere Temperatur bei gleichzeitig hoher mechanischer Beanspruchung (Fliehkraft und Gaskräfte) aushält $\left(\boldsymbol{\eta}_{\mathrm{i}}=1-\left(T_{\mathrm{A}} / T_{\mathrm{V}}\right)=1-(950 \mathrm{~K} / 1900 \mathrm{~K})=\mathbf{0 , 5 0}\right)$. Deshalb hat eine Gasturbine grundsätzlich einen schlechteren Carnot-Wirkungsgrad als ein Hubkolbenmotor. 
Der reale Wirkungsgrad $\eta$ der Vkm wird als das Verhältnis der von der Vkm abgegebenen mechanischen Arbeit $W_{\mathrm{M}}\left(\left[W_{\mathrm{M}}\right]=\mathrm{Nm}\right)$ zum unteren Heizwert $\mathrm{H}_{\mathrm{u}}\left(\left[\mathrm{H}_{\mathrm{U}}\right]=\mathrm{J} / \mathrm{kg}\right)$ mal der Masse $m_{\mathrm{K}}$ des verwendeten Kraftstoffes verstanden: $\eta=W_{\mathrm{M}} /\left(m_{\mathrm{K}} \cdot H_{\mathrm{v}}\right)$ [24]. Lkw Dieselmotoren haben im Bestpunkt einen Wirkungsgrad von $45 \%$ [24], großvolumige, langsam laufende Schiffsdieselmotoren (Kreuzkopfmotoren) von $54 \%$ [24]. Die bei der Drehzahl $n\left([\mathrm{n}]=\mathrm{s}^{-1}\right)$ arbeitende $\mathrm{Vkm}$ treibt einen Generator mit dem Drehmoment $M_{\mathrm{Vkm}}\left(\left[M_{\mathrm{M}}\right]=\mathrm{Nm}\right)$ an. Das Drehmoment $M_{\mathrm{vkm}}$ ergibt sich aus der Vkm Leistung $P_{\mathrm{vkm}}\left(\left[\mathrm{P}_{\mathrm{Vkm}}\right]=\mathrm{W}\right) \mathrm{zu} M_{\mathrm{vkm}}=P_{\mathrm{Vkm}} /(2 \pi \mathrm{n})$. Wenn man die Vkm nur bei einer Drehzahl und einer Last betreibt und diesen Arbeitspunkt konstruktiv optimiert, kann der thermische Wirkungsgrad $\eta$ auch von kleinvolumigen Viertaktmotoren auf $50 \%$ und bei zusätzlicher Nutzung von Abgasenergierückgewinnung bis auf annähernd $60 \%$ gesteigert werden [25].

Abgasenergierückgewinnung zur Wirkungsgradsteigerung einer Vkm ist nicht neu, bereits um 2005 haben sich Firmen wie BMW und heat2power SARL intensiv mit der Materie auseinandergesetzt [28] und [29]. Eine marktkonforme Umsetzung ist aber bisher daran gescheitert, dass eine $\mathrm{Vkm}$ in einem Fahrzeug ohne elektrischen Antriebsstrang über einen großen Lastund Drehzahlbereich betrieben werden muss. Damit schwanken je nach Betriebspunkt die Abgastemperatur und -energiemenge stark, womit die Abgasenergie nicht effizient in elektrische Energie $W_{\mathrm{el}}$ konvertiert werden kann.

Zum Thema Emissionen ist festzuhalten, dass Fahrzeughersteller zur Erfüllung der aktuellen Emissionslimits viel Zeit und Geld in die motorbaureihenspezifische Anpassung der Abgasnachbehandlungssysteme konventioneller Kraftfahrzeuge investieren müssen. Hierbei sind neben den Zusatzkosten die immer strikteren Emissionslimits und der dynamische Betrieb der Vkm über einen möglichst großen Last- und Drehzahlbereich DIE dominanten Herausforderungen. Wenn - wie bei konventionellen Kraftfahrzeugen üblich - der gesamte mögliche Lastund Drehzahlbereich der Vkm statisch wie dynamisch ausgenutzt werden soll, liegen - so wie bei einem Kaltstart - nicht alle Betriebspunkte in einem Abgastemperaturfenster, das eine klaglose Emissionsreduktion sicherstellt und es müssen zusätzliche last- und drehzahlabhängige Maßnahmen vorgesehen werden, um die Emissionsgrenzwerte zu erfüllen.

Bei einem konventionellen Kraftfahrzeug tritt ein „Kaltstart“ nur beim Starten der Vkm auf und die Aufwärmzeit der Abgasanlage bis zur Betriebstemperatur ist in der Regel kurz gegenüber der Betriebsdauer der Vkm bis zum Ende der Fahrt. Bei einem „Punktmotor", also einer Vkm, die entweder stillsteht oder nur bei einer Drehzahl und einer fixen Last betrieben wird, kann möglicherweise ein „Kaltstart“ mehrfach während einer Fahrt auftreten, da die in einem Speicher bereitgestellte elektrische Energie nicht ausreicht, um die gewünschte Fahrstrecke rein elektrisch zurückzulegen. Da der „Punktmotor“ starr mit einem elektrischen Generator verbunden ist, besteht z.B. die Möglichkeit bei einem „Kaltstart" den „Punktmotor“ mit dem als Elektromotor verwendeten Generator anzutreiben und erst dann Kraftstoff in den „Punktmotor" einzuspritzen, bis das Abgasnachbehandlungssystem die Betriebstemperatur erreicht hat. Man verschenkt damit etwas Wirkungsgrad, stellt aber geringstmögliche Emissionen sicher.

Bei modernen Kraftfahrzeugen mit Start/Stopp Automatik dürfte bei Motorstopp das Abkühlproblem des Abgasnachbehandlungssystems bereits gelöst sein, da bei diesen Fahrzeugen ein oftmaliger Start/Stopp der Vkm zulässig ist ohne dass dadurch die strengen Emissionslimits überschritten werden.

Der Betrieb einer Vkm in einem Arbeitspunkt bei fixer Last und Drehzahl liefert eine durch die Konstruktion der Vkm festgelegte konstante Wärmeenergiemenge bei konstanter Temperatur. Da ein rein stationärer Betrieb der Vkm vorliegt, kann davon ausgegangen werden, dass die Erreichung der Emissionslimits mit einem „Punktmotor“ generell leichter zu erfüllen sein 
werden, als mit einer in einem konventionellen Kraftfahrzeug verbauten und dynamisch betriebenen $\mathrm{Vkm}$.

Weiters eröffnet sich die Chance, mit Hilfe einer effizienten Abgasenergierückgewinnung (Waste-Heat Recovery) und Umwandlung der thermischen Energie in elektrische Energie $W_{\text {WHR }}$, den Wirkungsgrad des „Punktmotors“ weiter zu steigern. Dank optimierter Verbrennung und Abgasenergierückgewinnung haben z.B. die in der Saison 2017 eingesetzten Formel 1 Rennmotoren an der Volllast bei ca. 700 PS einen Gesamtwirkungsgrad $\eta_{\Sigma}$ von ca. 50 \% [32] erreicht. Der Rennmotor treibt die Hinterräder über ein mechanisches Getriebe an und die aus der Abgasenergie zusätzlich gewonnene elektrische Energie $W_{\text {WHR }}$ erhöht mittels eines Elektromotors das Drehmoment an der Hinterachse. Die elektrische Energie $W_{\text {WHR }}$ erhält der Elektromotor von einem hochdrehenden Generator, der von einer Gasturbine angetrieben, die Wärmeenergie aus dem Überschuss-Abgasmassenstrom des VkmTurboladers bezieht.

Für Serienanwendungen bestehen mehrere Möglichkeiten Abgaswärmeenergie in elektrische Energie umzuwandeln, wie beispielsweise mit Peltier-Elementen, einer Abgasturbine, einem Dampfkreislauf mit Dampfturbine oder einer Kombination der genannten Maßnahmen [29]. Es besteht auf diesem Gebiet großer Forschungsbedarf, um das bereits Erreichte weiter zu verbessern und zu kostengünstigen, effizienten und serientauglichen Lösungen für Fahrzeuge zu kommen. Hochwertige Ingenieurkunst ist hier gefragt, die grundlegenden Zusammenhänge der Thermodynamik sind längst bekannt. Wenn bedeutende Fahrzeug- respektive Motorenhersteller das Thema ernsthaft angehen, könnten in wenigen Jahren Fahrzeuge in Kundenhand den Beweis antreten. Das Optimierungspotenzial wird nie gänzlich ausgeschöpft sein, wie Verbrennungsmotoren seit über 150 Jahren zeigen.

Eine aus der Formel 1 abgeleitete und optimierte $\mathrm{Vkm}$, die in nur einem Arbeitspunkt betrieben wird („Punktmotor") und zusätzlich Abgasenergierückgewinnung nutzt (diese Kombination wird als "Fuel-Converter" bezeichnet), kann einen noch höheren Wirkungsgrad als heutige Formel 1 Motoren erreichen, da bei vorgegebener Kraftstoffmenge nicht die maximale Leistung bei minimalem Gewicht das Optimierungskriterium ist, sondern ein minimaler Verbrauch bei leistbarem technischen Aufwand. Zur Spezifizierung des in Abb. $\mathbf{3}$ ausgeführten Fuel-Converters werden die folgenden Annahmen getroffen:

- Die optimierte $V \mathrm{~km}$ hat eine Kurbelwellenleistung $P_{\mathrm{Vkm}}\left(\left[\mathrm{P}_{\mathrm{Vkm}}\right]=\mathrm{W}\right)$ von $50 \mathrm{~kW}(\approx 68 \mathrm{PS})$ und einen Wirkungsgrad $\eta_{\mathrm{VKM}}=W_{\mathrm{M}} /\left(m_{\mathrm{K}} \cdot H_{\mathrm{U}}\right)$ von $50 \%$ [25].

- Das Kurbelwellendrehmoment $M_{\mathrm{M}}$ der Vkm wird über einen Generator mit nachgeschaltetem Gleichrichter mit dem Gesamtwirkungsgrad $\eta_{\mathrm{GG}}=93 \%$ (Generator $\eta_{\mathrm{GE}}=95 \%$ [34] und Gleichrichter $\eta_{\mathrm{GR}}=98 \%$ ) in elektrische Energie $W_{\mathrm{el}}$ umgewandelt.

- Abb. 3 zeigt zwei Ausführungsvarianten 1) und 2), die wahlweise aus dem heißen VkmAbgas elektrische Energie gewinnen. Sie unterscheiden sich im apparativen Aufwand und dem daraus resultierenden Wirkungsgrad der Abgasenergierückgewinnung.

$50 \%$ der Kraftstoffenergie (100 kWs) werden von der Vkm in mechanische Arbeit und $50 \%$ in Motorabwärme gewandelt (50 kWs). $40 \%$ der Motorabwärme (20 kWs) hat relativ geringe Temperatur (Kühlwasser, Motoröl, Konvektionskühlung und Strahlungswärme heißer Teile) und steht zum Teil zur Fahrzeugklimatisierung zur Verfügung. $60 \%$ der Motorabwärme (30 kWs) ist heißes Abgas mit ca. $800^{\circ} \mathrm{C}$ und kann zur Abgasenergierückgewinnung genutzt werden.

- Ausführungsvariante 1): Eine Abgasturbine nutzt $30 \%$ der Abgasenergie $W_{\text {ht }}$ und wandelt diese mit $30 \%$ Wirkungsgrad [33] in elektrische Energie $W_{\text {WHR1 }}$ um. 
- Ausführungsvariante 2): In einer aufwändigeren Anordnung kann mit Gasturbine 2, einem nachgeschalteten Abhitzkessel und einer Dampfturbine (oder Ranking Cycle) die Abgasenergie $W_{\text {ht }}$ mit 40 bis $50 \%$ Wirkungsgrad in die elektrische Energie $W_{\text {WHR2 }}$ umgewandelt werden [21], [28] und [29].

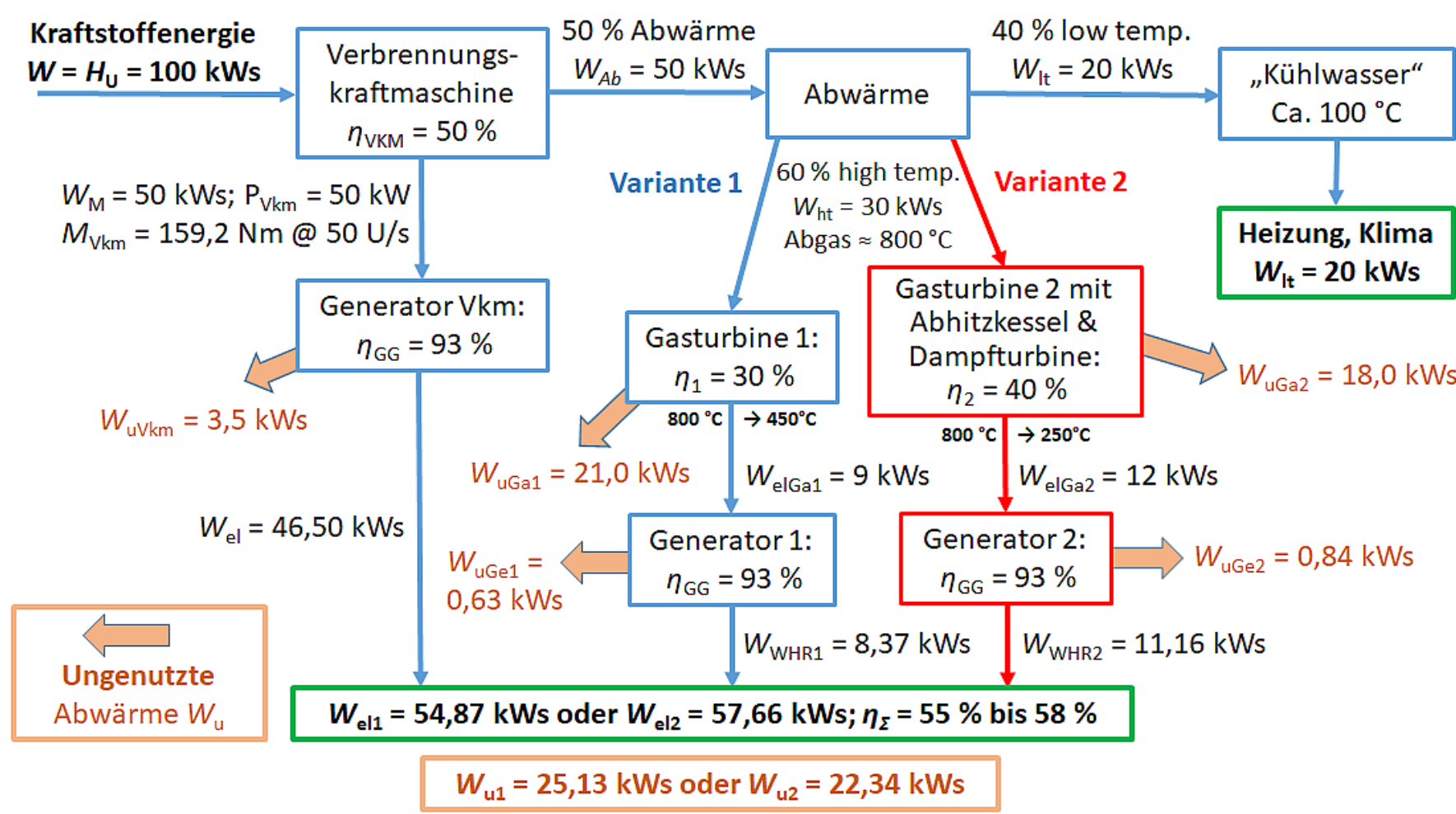

Abb. 3: Wirkungsgradabschätzung eines Fuel-Converters: Hochwirkungsgrad-Vkm mit Abgasenergierückgewinnung, die bei fixer Last und Drehzahl betrieben wird und im Fahrzeug aus flüssigem Kraftstoff elektrische Energie erzeugt.

- Die in einem Kühlkreislauf bei ca. $100^{\circ} \mathrm{C}$ anfallende Restabwärme $W_{\text {It }}$ der Vkm und die Restwärme der Abgasenergierückgewinnung kann man für Heizung oder Kühlung des Fahrzeuges einsetzen. Es gilt für die ungenutzte Abwärme $W_{U}=H_{U}-W_{\mathrm{el}}-W_{\mathrm{lt}}$.

Der in Abb. 3 dargestellte Fuel-Converter hat in der Ausführung gemäß „Variante 1" einen Gesamtwirkungsgrad $\eta_{\Sigma}=\left(W_{\mathrm{el}}+W_{\mathrm{WHR} 1}\right) / H_{\mathrm{U}}$ von ca. $\underline{55 \%}$ und in der "Variante 2 " einen Gesamtwirkungsgrad $\eta_{\Sigma}=\left(W_{\mathrm{el}}+W_{\mathrm{WHR} 2}\right) / H_{U}$ von ca. $58 \%$. Die Bandbreite des Wirkungsgrades $\eta_{\Sigma}$ ist vom technischen und damit auch vom finanziellen Aufwand, den man in die Abgasenergierückgewinnung investieren will, abhängig.

Ein rasch umsetzbarer Ansatz zur Senkung der verkehrsbedingten $\mathrm{CO}_{2}$ Emissionen wäre die zügige Umstellung auf Hybridfahrzeuge mit Fuel-Converter, da Abb. 2 und Tabelle $\mathbf{5}$ zeigen, dass mit dem aktuellen globalen Strommix von $518 \mathrm{~g} \mathrm{CO}_{2}-\mathrm{eq} / \mathrm{kWh}$ keine signifikanten $\mathrm{CO}_{2}$ Einsparung durch batterieelektrische Fahrzeuge erzielt werden kann.

Der hervorragende Gesamtwirkungsgrad eines Fuel-Converters von über $50 \%$ und die daraus ableitbare geringe $\mathrm{CO}_{2}$ Belastung von Hybridfahrzeugen mit Fuel-Converter sollten als Messlatte dienen, wie hoch die $\mathrm{CO}_{2}$ Belastung für die Bereitstellung der elektrischen Energie in einem Land maximal sein darf, damit ein Staat Förderungen für batterieelektrische Fahrzeuge vergibt. 


\section{Kurzfristspeicherung der elektrischen Energie im Fahrzeug}

Beim privaten Fahrzeugkauf bestimmen vorwiegend Emotionen die Entscheidung für oder gegen ein gewisses Fahrzeugmodell. Dabei spielt neben dem Styling und dem gebotenen Komfort, der Kraftstoffverbrauch $\left(\mathrm{CO}_{2}\right.$ Emissionen) und die vom Fahrzeug gebotene Fahrdynamik eine entscheidende Rolle. Das unmittelbare Ansprechen auf die Fahrpedalstellung und die hohe Fahrzeugbeschleunigung sind hierbei entscheidend. Diese Eigenschaften werden von einem elektrischen Antriebsstrang ideal erfüllt. Fahrzeuge mit Vkm müssen komplizierte und teure Systeme in die Vkm und in das Getriebe einbauen, um nur annähernd an die Agilität und die Beschleunigungscharakteristik eines elektrischen Antriebsstranges heranzukommen. Die von Kunden geforderte hohe Beschleunigung führt bei Vkm auf irrwitzig hohe Motorleistungen, die als „Abfallprodukt“ Höchstgeschwindigkeiten ergeben, die im öffentlichen Verkehr gefährlich sind und deshalb typisch bei $250 \mathrm{~km} / \mathrm{h}$ abgeregelt werden. Weiters verkomplizieren und verteuern die hohen Dynamikanforderungen an die Vkm die immer härter werdenden Emissionsvorschriften der Abgasnachbehandlungssysteme.

Hohe Fahrdynamik ist für eine effizient arbeitende Abgasnachbehandlung kontraproduktiv und die Lösung dieses Zielkonfliktes wird Jahr für Jahr schwieriger, da die Emissions- und Verbrauchsbestimmungen immer strenger werden. Diese Situation ist eine offensichtliche Sackgasse, aus der man mit einem elektrischen Antriebsstrang elegant herauskommt. Der Fuel-Converter ist von der maximalen Beschleunigung des Fahrzeuges vollständig entkoppelt und damit sind auch dessen Schadstoffemissionen von der Fahrdynamik vollständig entkoppelt und immer gleichbleibend. Hohe Fahrdynamik wird den Durchschnittsverbrauch des Fahrzeuges vergrößern aber nicht die Reichweite, da der Flüssigkeitstank des FuelConverters nur mit geringfügiger Gewichtszunahme| ${ }^{7}$ des Fahrzeuges nahezu beliebig groß gemacht werden kann.

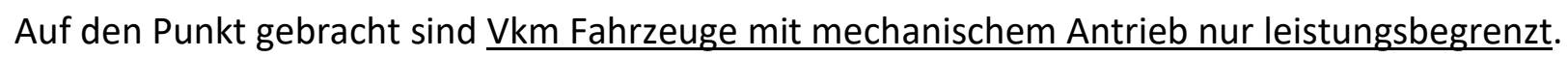
Die für den Betrieb notwendige Kraftstoffenergie sorgt quasi für unlimitierte Fahrstrecken und hängt nur von der Tankgröße ab. Batterieelektrische Fahrzeuge sind kaum leistungslimitiert, sondern energie- und damit reichweitenbegrenzt.

$I^{7}$ Ein Kraftstofftank aus Kunststoff mit 22 I Inhalt hat ca. 2,0 kg und mit 43 I ca. 4,3 kg [53]. Bei 4 I/100 km Kraftstoffverbrauch des Fuel-Converters kann die Reichweite des Fahrzeuges von ca. 550 km durch die Erhöhung des Tankgewichtes um 2,3 kg plus ca. 16 kg Kraftstoff auf gut 1000 km mehr als verdoppelt werden. 
Die Kurzfristleistung eines elektrischen Antriebsstranges ist quasi unbegrenzt und hängt bei einem batterieelektrischen Fahrzeug nahezu nur von der Leistungsfähigkeit des im Fahrzeug befindlichen elektrischen Energiespeichers ab. Die optimale Lösung und der Ausweg aus der Misere scheinen eine Kombination aus dem Besten zweier Welten zu sein; also ein Hybridfahrzeug: Es liefert sehr gute Fahrdynamik (elektrisches Beschleunigen und Bremsen) und durch die Kraftstoffbetankung des Fahrzuges in Kombination mit dem Fuel-Converter die heute üblichen Reichweiten von 700 bis 900 km je Tankfüllung.

Die am Markt verfügbaren Konzepte, wie Serienhybrid, Parallelhybrid, Power-Split Hybrid, etc., konnten das Versprechen bisher nicht einlösen, bei gleicher Fahrleistung den Verbrauch und die Emissionen in Kundenhand deutlich zu senken. Die Ursache liegt einerseits im erhöhten Fahrzeuggewicht, das durch die Hybridisierung hervorgerufen wird und andererseits im Betrieb der Vkm in einem großen Kennfeldbereich mit zum Teil miserablen Wirkungsgraden.

Hybridisierung wird erst dann sinnvoll, wenn die Vkm nur mehr als Fuel-Converter im optimierten Bestpunkt beim höchsten Wirkungsgrad betrieben wird.

Ein Element fehlt allerdings noch in der Kette des elektrischen Antriebsstranges und dieses Element ist ein elektrischer Energiespeicher - im Folgenden als „Power-Tank“ bezeichnet -, der hohe elektrische Leistungen aufnehmen und abgeben kann, hunderttausende Lastspiele ohne wesentliche Alterung verkraftet und aus Gewichtsgründen nur so viel Energie speichert, wie für den dynamischen Betrieb des Fahrzeuges notwendig ist. Die mittlere elektrische Energie, die man zum Fahren mit Heizung und Klimaanlage benötigt, wird vom Fuel-Converter bereitgestellt und dieser benötigt zur Betankung flüssige Kraftstoffe, welche die von Vkm Fahrzeugen gewohnten Fahrstrecken und Betankungszeiten ermöglichen.

Die Generatorausgangsleistung des Fuel-Converter muss nur so groß sein, wie die verlangte Dauerhöchstgeschwindigkeit des Fahrzeuges. Bei einem Mittelklassefahrzeug benötigt man gemäß Abb. 1 bei $80 \mathrm{~km} / \mathrm{h}$ am Rad ca. 8,1 kW, bei $100 \mathrm{~km} / \mathrm{h}$ ca. 12,9 kW, bei $130 \mathrm{~km} / \mathrm{h}$ ca. $23,6 \mathrm{~kW}$, bei $150 \mathrm{~km} / \mathrm{h}$ ca. 33,7 kW und bei $180 \mathrm{~km} / \mathrm{h}$ ca. $54 \mathrm{~kW}$. Welche Leistung tatsächlich gewählt wird, liegt am Kundenkreis und am Markt, den ein Fahrzeughersteller mit seinen Modellen adressieren will.

Die elektrische Leistung des Power-Tanks legt die Leistung, die Dynamik und die Höchstgeschwindigkeit eines Fahrzeuges fest, der elektrische Energieinhalt des Power-Tanks bestimmt, wie lange bzw. wie weit das Fahrzeug rein elektrisch fahren kann, bevor der Fuel-Converter automatisch in Betrieb genommen wird, um den Power-Tank nachzuladen.

Zur Klärung, welche elektrischen Speicher für das Anforderungsprofil des Power-Tanks geeignet sind, werden im Folgenden die Spezifikationen aus einem Lebensdauerzyklus erarbeitet.

Zum optionalen emissionsfreien Betrieb des Fahrzeuges, z.B. in Ballungsräumen, dient quasi als Ersatz des Fuel-Converters für eine Fahrstrecke von ca. 100 km eine zusätzliche Hochenergiebatterie, wie in Kapitel 3 „Batterien als Energiespeicher" ausgeführt.

\section{Power-Tank Realisierungsvariante}

Hohe Beschleunigung und hohe Rekuperationsleistung (Nutzbremsung) verlangen einen leistungsstarken elektrischen Antriebsstrang mit einem leistungsstarken Power-Tank. Ein Mittelklassefahrzeug mit einer Masse von $1.500 \mathrm{~kg}$, das von Null auf $100 \mathrm{~km} / \mathrm{h}$ in ca. neun 
Sekunden beschleunigt, erfüllt diese Bedingung und benötigt dafür ca. $80 \mathrm{~kW}$ Antriebsleistung $\left.\right|^{8}$. Wenn vom Fahrzeug eine Dauerhöchstgeschwindigkeit $v_{\text {avg-max }}$ von ca. $140 \mathrm{~km} / \mathrm{h}$ erwartet wird, folgt aus Abb. 1, dass die mechanische Antriebsleistung $P_{\text {mech }}$ des Fahrzeugs $30 \mathrm{~kW}$ und damit die elektrische DC-Ausgangsleistung $P_{\mathrm{DC}}$ des Fuel-Converter ca. $35 \mathrm{~kW}$ betragen muss. In diesem Betriebszustand ist das Hybridfahrzeug ein reiner Serienhybrid, dessen elektrischer Energiespeicher (Power-Tank) weder geladen noch entladen wird. Hierbei sind die folgenden Wirkungsgrade angenommen:

Fuel-Converter: $\eta_{\Sigma}=54,87 \%$... Elektrische DC Ausgangsleistung $P_{\mathrm{el}}$ des Generators bezogen auf den Heizwert $H_{\cup}$ des Kraftstoffs; siehe Kapitel 7.

Power-Tank: $\eta_{\mathrm{PT}}=92 \%$... Von der Fahrdynamik abhängige mittlerer Round-Trip Wirkungsgrad des elektrischen Energiespeichers; siehe Tabelle 2.

Elektrischer Antriebsstrang motorisch: $\eta_{\Sigma}=84,5 \% \ldots$ Mittelwert der DC-Eingangsleistung $P_{\mathrm{DC}}$ am Umrichter zu Antriebsleistung $P_{\text {mech }}$ am Rad.

Elektrischer Antriebsstrang generatorisch (Nutzbremsen): $\eta_{\Sigma}=92 \%$... Mittelwert der DCEingangsleistung $P_{\mathrm{DC}}$ am Umrichter zu Antriebsleistung $P_{\text {mech }}$ am Rad.

Der Kraftstoffverbrauch des hier präsentierten Serienhybrids beträgt bei konstant $140 \mathrm{~km} / \mathrm{h}$ 5,13 Liter Benzin oder 4,61 Liter Dieselkraftstoff pro $\left.100 \mathrm{~km}\right|^{9}$.

Im Alltagsbetrieb ist eine permanente Konstantfahrt mit $140 \mathrm{~km} / \mathrm{h}$ nur in wenigen Ausnahmefällen möglich. Man benötigt zur Erfüllung der Fahraufgaben zusätzlich einen elektrischen Hochleistungs-Energiespeicher (Power-Tank), der die elektrische Energie für den dynamischen Fahrbetrieb bei beliebigen Geschwindigkeiten zur Verfügung stellt und der FuelConverter sorgt dafür, dass der Power-Tank von Zeit zu Zeit aufgeladen wird.

Zur Bestimmung der Lebensdauer eines Power-Tanks in Bezug auf Zyklenanzahl und Betriebszeit ist ein Testzyklus notwendig. Mit Hilfe des Testzyklus werden die Anzahl an Lade-/Entladezyklen und die Betriebsdauer ermittelt, die ohne wesentliche Einbuße der Leistungsfähigkeit des Speichers bereitgestellt werden müssen.

Unter Extrembedingungen darf die fehlerkritische Komponente „Power-Tank“ nur mit einer für einen aktuellen mechanischen Antriebsstrang vergleichbaren Ausfallrate versagen, da im Fehlerfall die Antriebsleistung des Fahrzeuges ausfällt und daraus ein hohes Unfallrisiko erwachsen kann.

Ein Test zur Feststellung der Zyklenfestigkeit muss an die Belastungsgrenzen der Komponenten gehen, da auch Fahrzeugkunden möglicherweise diese Grenzen ausloten werden. Übliche Fahrzyklen, wie NEFZ und ARTEMIS [30] oder WLTP [31], sind für den hier benötigten Zweck ungeeignet, da sie zur Ermittlung des Kraftstoffverbrauches und der $\mathrm{CO}_{2}$ Emissionen von Fahrzeugen bei schonender Fahrweise gestaltet sind und nicht zum Ausloten der Grenzbelastung von Fahrzeugkomponenten.

Die Lebensdauer eines Power-Tanks leidet bei elektrochemischen Speichern am stärksten, wenn hohe und langanhaltende Lade- und Entladeströme die Verlustleistung und damit die Eigenerwärmung des Speichers maximieren. Hohe Lade- und Entladeströme entstehen, wenn

$1^{8}$ Sie Realisierungsvarianten in den Kapiteln 10.2.1 Batterien, 10.2.2 Kondensatoren und 10.2.3 Schwungrad.

| ${ }^{9}$ Bei $140 \mathrm{~km} / \mathrm{h}$ Fahrgeschwindigkeit und der dafür benötigten elektrischen Ausgangsleistung $P_{\mathrm{el}}$ des FuelConverters von $35 \mathrm{~kW}$ (Wirkungsgrad $\eta_{\Sigma}=54,87 \%$ ) ist die benötigte Kraftstoffenergie $H_{\mathrm{u}}=45,56 \mathrm{kWh}$ pro $100 \mathrm{~km}=(35 \mathrm{~kW} / 0,5487) *(100 / 140)$. Der Heizwert $H u$ von Benzin ist 8,89 kWh/Lit. und von Dieselkraftstoff $9,88 \mathrm{kWh} /$ Lit. [40]. 
der Straßenverlauf stark wechselndes Gefälle aufweist und das Fahrzeug dynamisch mit oftmals wechselnder und hoher Geschwindigkeit betrieben wird. Ein Testzyklus, der diese Fahrweise abbildet, weist grundsätzlich eine hohe Durchschnittsgeschwindigkeit auf, woraus folgt, dass eine Fahrzeugbetriebsstunde im Testzyklus eine signifikant größere Fahrstrecke als die typischen $50 \mathrm{~km}$ bis $60 \mathrm{~km}$ aufweisen wird. Demnach wird die kilometerbezogene Fahrzeuglebensdauer $T_{\mathrm{k}}$ von z.B. $300.000 \mathrm{~km}$ in signifikant kürzerer Zeit erreicht werden, als die von einem Fahrzeug erwartete Betriebslebensdauer $T_{z}$ von z.B. 5.000 Stunden.

Der zum Testen erarbeitete Zyklus belastet den Power-Tank so wie beschrieben und entnimmt dabei $75 \%$ der Speicherkapazität (Depth Of Discharge, DOD) bevor durch Aufladen der zu Beginn des Zyklus herrschende Ladezustand (State Of Charge, SOC) wiederhergestellt wird. Während der gesamten Testzeit benötigen elektrische Nebenaggregate eine elektrische Leistung von $P_{\mathrm{NA}}=2 \mathrm{~kW}$. Der aus drei Schritten bestehende und im Folgenden genauer dargelegte Testzyklus, wird so lange wiederholt, bis die kilometerbezogene Fahrzeuglebensdauer $T_{\mathrm{k}}$ erreicht ist.

1) Überholen:

a) Beschleunigen des Fahrzeuges mit der Maximalleistung $P_{\mathrm{M}}$ von der Geschwindigkeit $v_{1}=100 \mathrm{~km} / \mathrm{h}$ auf die Geschwindigkeit $v_{2}=150 \mathrm{~km} / \mathrm{h}$,

b) Konstantfahrt mit $v_{2}=150 \mathrm{~km} / \mathrm{h}$ für 10 Sekunden,

c) elektrisches Abbremsen mit der Maximalleistung $P_{M}$ von der Geschwindigkeit $v_{2}=150 \mathrm{~km} / \mathrm{h}$ auf die Geschwindigkeit $v_{1}=100 \mathrm{~km} / \mathrm{h}$,

d) Konstantfahrt mit der Geschwindigkeit $v_{1}=100 \mathrm{~km} / \mathrm{h}$ für 10 Sekunden und

e) Wiederholung des Überholvorganges 1a) bis 1d) bis der Ladezustand (DOD) des Power Tanks den minimal zugelassenen Wert erreicht hat $(75 \%$ des Power-Tank Energieinhaltes sind entnommen).

\section{2) Nachladen:}

Starten des Fuel-Converter mit Hilfe des eingebauten Generators und Konstantfahrt mit der Geschwindigkeit $v_{1}$ bis der Power-Tank vollgeladen ist. Die Ladeleistung $P_{\text {chg }}$ ergibt sich aus der Differenz der Fuel-Converter Leistung $P_{\mathrm{FC}}$ und der für die Fahrt mit der Geschwindigkeit $v_{1}$ aus Abb. 1 entnommenen Leistung $P_{\mathrm{v} 1}$, vermehrt um die für den Betrieb der Nebenaggregate benötigten Leistung $P_{\mathrm{NA}}: P_{\mathrm{chg}}=P_{\mathrm{FC}}-P_{\mathrm{v} 1}-P_{\mathrm{NA}} \forall v \mid P_{\mathrm{v} 1}+P_{\mathrm{NA}}<P_{\mathrm{FC}}$.

3) Der Test beginnt wieder mit dem Zyklusschritt 1) und wird solange wiederholt bis die geforderte kilometerbezogene Lebensdauer $T_{\mathrm{k}}$ des Power-Tanks erreicht ist. Die Durchschnittsgeschwindigkeit $v_{\text {afg }}$ des Tests ergibt sich aus der pro Testzyklus zurückgelegten Strecke und der dafür benötigten Zeit.

Die folgende Tabelle 2 präsentiert neben der Anzahl $k$ an Zyklen für die kilometerbezogene Lebensdauergrenze von $300.000 \mathrm{~km}$ zusätzlich wertvolle Informationen über das Lastkollektiv mit dem der Power-Tank betrieben wird.

Für den Testzyklus wird ein mit Lithiumtitanat-Batteriezellen von Toshiba (10 Ah SCiB ${ }^{\mathrm{TM}}$ ) [10] aufgebauter Power-Tank eingesetzt. Die Anzahl der Zellen und damit das Gewicht und die Kosten des Power-Tanks errechnen sich aus der maximal zulässigen Leistung, die vom Hersteller für die Zellen festgelegt ist (siehe Kapitel 10.2.1). Insgesamt kommen 167 Zellen mit einer Gesamtmasse von 85,2 kg zum Einsatz. 
Tabelle 2 Berechnung der Zyklenzahl eines Power-Tanks mit 4,09 kWh Energieinhalt und 80 kW Maximalleistung aus den Betriebsdaten eines verbrauchsoptimierten Hybridfahrzeuges mit Fuel-Converter für 300.000 km Laufleistung.

\begin{tabular}{|c|c|c|c|c|c|c|}
\hline \multirow{3}{*}{$\begin{array}{l}\text { Masse } m=1500 \mathrm{~kg} \text {, Gesc } \\
\text { aggregate } P_{\mathrm{NA}}=2 \mathrm{~kW} \text {, Fu } \\
\text { Energieinhalt } W_{\mathrm{PT}}=4,09 \\
\text { 1a) } 7 \mathrm{mal} \text { Beschleunigen } \\
\text { von } v_{1}=100 \mathrm{~km} / \mathrm{h} \text { auf } v_{2}\end{array}$} & & $\operatorname{ter} P_{\mathrm{FC}}=3$ & Lebensdauer & $\begin{array}{l}\text { avg-max }=14 \mathrm{U} \\
\mathrm{ax}=80 \mathrm{~kW}, P_{\mathrm{C}} \\
5.000 \mathrm{~h} \text { und }\end{array}$ & & kW, \\
\hline & \multicolumn{2}{|c|}{ Dauer in Sek. } & \multirow{2}{*}{$\begin{array}{c}\text { Dauer in Min. } \\
1,928\end{array}$} & \multirow{2}{*}{$\begin{array}{c}\text { Strecke in km } \\
4,129\end{array}$} & \multicolumn{2}{|c|}{ Energie in $\mathrm{kWh}$} \\
\hline & \multicolumn{2}{|c|}{$\begin{array}{c}\mathbf{7} \cdot \mathbf{1 6 , 5} \quad(12,0 \% \\
\left.@ P_{\mathrm{PT}}=80 \mathrm{~kW}\right)\end{array}$} & & & \multicolumn{2}{|r|}{$-2,564$} \\
\hline $\begin{array}{l}\text { 1b) } 7 \mathrm{mal} v_{2}=150 \mathrm{~km} / \mathrm{h} \\
\text { für } 10 \text { Sekunden }\end{array}$ & \multicolumn{2}{|c|}{$\begin{array}{l}6 \cdot 10+6,\left.1\right|^{10}(6,9 \% \\
\left.@ P_{\mathrm{PT}}=44,3 \mathrm{~kW}\right)\end{array}$} & 1,102 & 2,754 & \multicolumn{2}{|r|}{$-0,813$} \\
\hline $\begin{array}{l}\text { 1c) } 7 \text { mal Nutzbremsen } \\
\text { mit } P_{M} \text { von } v_{2} \text { auf } v_{1}\end{array}$ & \multicolumn{2}{|c|}{$\begin{array}{c}7 \cdot 6,7 \quad(4,9 \% \\
\left.@ P_{\mathrm{PT}}=80 \mathrm{~kW}\right)\end{array}$} & 0,783 & 1,652 & \multicolumn{2}{|c|}{$+1,052$} \\
\hline $\begin{array}{l}\text { 1d) } 6 \text { mal } v_{1}=100 \mathrm{~km} / \mathrm{h} \\
\text { für } 10 \text { Sekunden }\end{array}$ & \multicolumn{2}{|c|}{$\begin{array}{l}6 \cdot 10 \quad(6,3 \% \\
\left.@ P_{\mathrm{PT}}=19,1 \mathrm{~kW}\right)\end{array}$} & 1,000 & 1,667 & \multicolumn{2}{|r|}{$-0,317$} \\
\hline Summen 1a) bis 1d) & \multicolumn{2}{|r|}{288,8 Sek. } & 4,813 Min & $10,202 \mathrm{~km}$ & \multicolumn{2}{|c|}{$\begin{array}{c}-3,694 \mathrm{kWh} \\
(+1,052 \mathrm{kWh})\end{array}$} \\
\hline $\begin{array}{l}\text { 2) Laden bei } v_{1} \text { mit } \\
15,9 \mathrm{~kW}=2,957 \mathrm{kWh}\end{array}$ & \multicolumn{2}{|c|}{$\begin{array}{l}669,6 \quad(69,9 \% \\
\left.@ P_{\mathrm{PT}}=15,9 \mathrm{~kW}\right)\end{array}$} & 11,160 & 18,600 & \multicolumn{2}{|c|}{$\begin{array}{l}-3,694 \\
+4,009\end{array}$} \\
\hline Zyklusdauer & \multicolumn{2}{|c|}{ 958,4 Sek. } & 11,16 Min. & $28,802 \mathrm{~km}$ & \multicolumn{2}{|c|}{$\eta_{\mathrm{PT}}=92 \%$} \\
\hline \multicolumn{2}{|c|}{ Mögliche zeitbez. Zyklen: $z=$} & 18.781 & \multicolumn{3}{|c|}{ Kilometerbezogene Zyklenzahl $k=$} & 10.416 \\
\hline \multicolumn{2}{|c|}{ Gesamte Betriebszeit (h) $T_{\mathrm{z}}=$} & 2.773 & \multicolumn{3}{|c|}{ Gesamte Kilometerleistung $(\mathrm{km}) T_{\mathrm{k}}=$} & 300.001 \\
\hline \multicolumn{5}{|c|}{ Durchschnittsgeschwindigkeit $(\mathrm{km} / \mathrm{h})$ des Testzyklus $v_{\text {avg }}=$} & \multicolumn{2}{|c|}{$108,2 \mathrm{~km} / \mathrm{h}$} \\
\hline \multicolumn{5}{|c|}{ Elektrischer Energieverbrauch pro 100 km: 35 kW während 69,9 \% der Zeit = } & \multicolumn{2}{|c|}{22,6 kWh } \\
\hline \multirow{2}{*}{\multicolumn{5}{|c|}{$\begin{array}{l}\text { Energieverbrauch Fuel-Converter ( } \eta_{\Sigma}=54,87 \% \text { ) pro } 100 \text { km: } H_{U}=41,19 \mathrm{kWh} \\
\text { Heizwert: Benzin: } H_{U}=8,89 \mathrm{kWh} / \text { Liter; Dieselkraftstoff: } H_{U}=9,88 \mathrm{kWh} / \text { Liter [38] }\end{array}$}} & \multicolumn{2}{|c|}{ 4,63 Lit Benzin } \\
\hline & & & & & 4,17 & Lit. Diesel \\
\hline
\end{tabular}
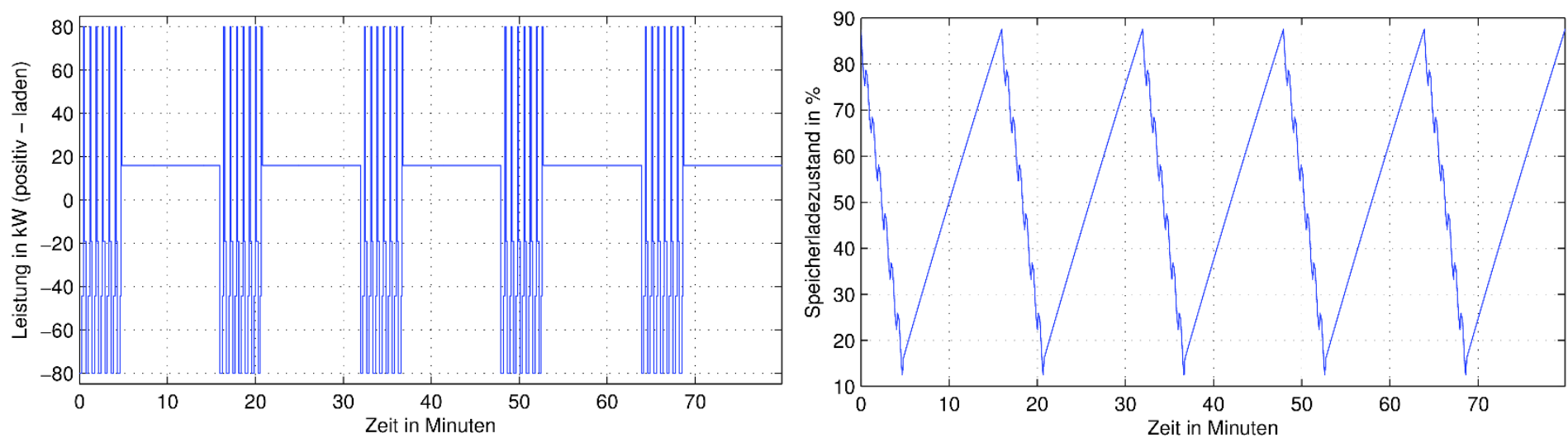

Abb. 4: Elektrische Leistung $P_{\mathrm{PT}}$ und Ladezustand DOD des Power-Tanks in Testzyklus

Wenn man im für den Testzyklus verwendeten Fahrzeug einen elektrischen Energiespeicher mit gleicher Power-Tank Leistung $P_{\mathrm{PT}}=80 \mathrm{~kW}$ einsetzt und den Energieinhalt des Speichers variiert, verhält sich die Zyklusdauer nahezu proportional und die Zyklusanzahl (= Lebensdauer

$1^{10}$ Beim siebten Zyklus dauerte die Konstantfahrt mit $v_{2}=150 \mathrm{~km} / \mathrm{h}$ statt 10 Sekunden nur mehr 6,1 Sekunden, da zu diesem Zeitpunkt der Power-Tank entladen war (75 \% DOD erreicht). 
des Power Tanks) nahezu umgekehrt proportional zum Energieinhalt. Für einen Power-Tank mit z.B. 2 kWh Energieinhalt würde der Fuel-Converter bereits nach drei Überholvorgängen anspringen und den Power-Tank in ca. 5 Minuten nachladen.
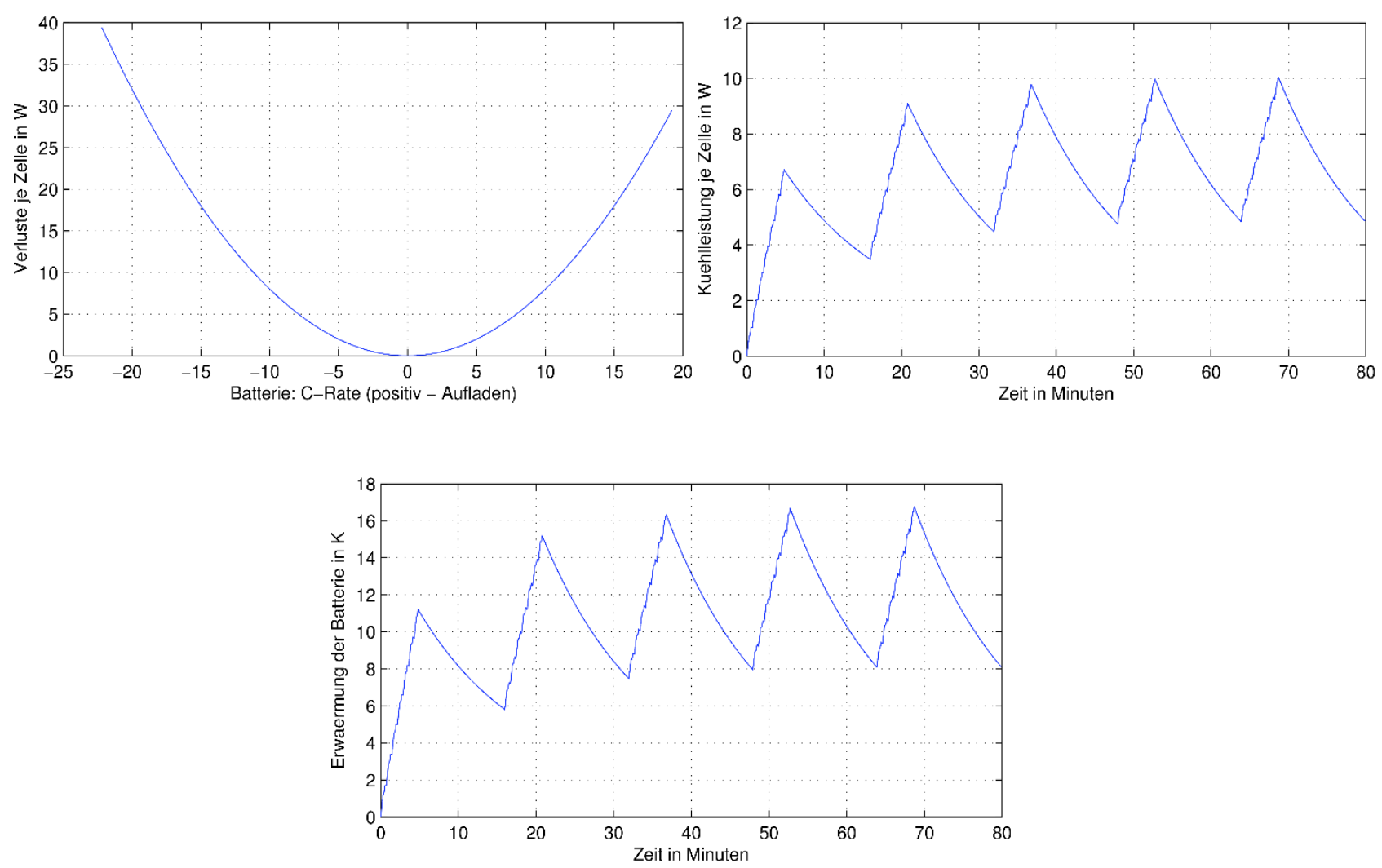

Abb. 5: Verlustleistung, Kühlleistung und Erwärmung des im Testzyklus verwendeten Batteriepacks, bestehend aus 167 Zellen der Lithiumtitanat-Batterie 10 Ah SCiB ${ }^{\mathrm{TM}}$ der Firma Toshiba. Mit ca. 1300 W Kühlleistung kann im Testzyklus die Erwärmung der Batterie um ca. $16^{\circ} \mathrm{C}$ begrenzt werden.

Tabelle 3 fasst die zur Auswahl geeigneter Speichertechnologien, die ermittelten $C$-Raten, Lastkollektive und Zyklenzahlen zusammen. Unter der $C$-Rate versteht man den Quotienten aus der Leistung $P_{\max }\left(\left[P_{\max }\right]=\mathrm{W}\right)$, die ein Speicher aufnimmt oder abgibt, im Verhältnis zur Energie $W_{\mathrm{PT}}\left(\left[W_{\mathrm{PT}}\right]=W h\right)$, die ein Speicher maximal speichern kann: $C=P_{\max } / W_{\mathrm{PT}}$.

Neben Kosten, Sicherheit, Zuverlässigkeit, Raumbedarf und Gewicht liefert das Lastprofil für den Power-Tank (siehe Tabelle 2 und Tabelle 3) mit der Energie $W_{\mathrm{PT}}=4,09 \mathrm{kWh}$ wichtige Daten, um einen passenden elektrischen Energiespeicher auszusuchen.

Die minimal notwendige Power-Tank Energie $W_{\mathrm{PT}}$ lässt sich größenordnungsmäßig aus der für eine Speichertechnologie charakteristischen maximal zulässigen $C$-Rate abschätzen. Für das vorstehende Beispiel wird eine maximale $C$ Rate von 20 angenommen.

$P_{\max }=80 \mathrm{~kW} \rightarrow C=20 \rightarrow 4 \mathrm{kWh}$ (davon werden $3 \mathrm{kWh}$ genutzt).

Für eine kilometerbezogene Lebensdauer von $300.000 \mathrm{~km}$ benötigt man mit diesem Speicher ca. 10.000 Ladezyklen mit 75 \% DOD. Diese durch den Testzyklus gefundenen Daten dienen dazu, im nächsten Kapitel geeignete Energiespeicher auszusuchen. 
Tabelle 3 Zusammenfassung der Lastkollektive und C-Raten eines Power-Tanks mit 4,09 kWh Energieinhalt bei einem verbrauchsoptimierten Fahrzeug

\begin{tabular}{|c|c|}
\hline$x^{2}+x^{2}$ & $\begin{array}{l}\text { Verbrauchsoptimiert } \\
\text { B) } W_{\mathrm{PT}}=4,09 \mathrm{kWh}\end{array}$ \\
\hline Lade- Entladetiefe (DOD) eines Power-Tank Zyklus & $75 \%=3,068 \mathrm{kWh}$ \\
\hline Zykluslänge und Zykluszeit & 28,802 km; 11,16 Min. \\
\hline Gesamte Betriebszeit & $2.773 \mathrm{~h}$ \\
\hline Anzahl $k$ der Zyklen für 300.000 km Laufleistung & 10.416 \\
\hline $\begin{array}{l}\text { Zeitlicher Anteil der Maximalleistung } P_{\max } \text { und } C \text { Rate im Zyklus } \\
\text { (Nutzbremsen = aufladen) }\end{array}$ & $\approx 20$ C: $80 \mathrm{~kW} @ 4,9 \%$ \\
\hline Aufladen des Power-Tanks mit den Fuel-Converter & $\approx 4$ C: 15,9 kW @ 69,9\% \\
\hline $\begin{array}{l}\text { Zeitlicher Anteil der Maximalleistung } P_{\max } \text { und } C \text { Rate im Zyklus } \\
\text { (entladen) }\end{array}$ & $\approx 20$ C: $80 \mathrm{~kW} @ 12,0 \%$ \\
\hline Leistung $P_{\mathrm{v} 2}$ bei der Geschwindigkeit $v_{2}=150 \mathrm{~km} / \mathrm{h}$ (entladen) & $\approx 11$ C: 44,3 kW @ 6,9\% \\
\hline \multirow[t]{2}{*}{ Leistung $P_{\mathrm{v} 1}$ bei der Geschwindigkeit $v_{1}=100 \mathrm{~km} / \mathrm{h}$ (entladen) } & $\approx 5$ C: 19,1 kW @ 6,3 \% \\
\hline & Insgesamt $100 \%$ \\
\hline
\end{tabular}

\section{Technologieauswahl für Power-Tanks}

Grundsätzlich stehen zur Realisierung eines Power-Tanks, also eines Speichers für elektrische Energie mit wenig Energieinhalt, der mit hohen $C$-Raten betrieben wird und im vorstehenden Beispiel mit 4 kWh ca. 10.000 Vollladezyklen als Betriebslebensdauer haben muss, drei physikalische Prinzipien zur Verfügung.

\subsection{Allgemeine Überlegungen zur Technologieauswahl}

Die Speicherung der elektrischen Energie kann

a) als Ladung (Elektronen) in einem Kondensator bei einer bestimmten Klemmenspannung oder

b) als reversible elektrochemische Reaktion wie beispielsweise bei Blei-Schwefelsäure, NickelCadmium und Nickel-Metallhydrid Batterien oder durch reversible Interkalation von lonen im Elektrodenmaterial wie beispielsweise bei Lithium-Ionen Batterien, erfolgen.

c) Das dritte Prinzip ist die Speicherung der Energie in einer schnell rotierenden Masse, die mit einer elektrischen Maschine verbunden ist, beim Laden die elektrische Energie in Rotationsenergie umwandelt und beim Entladen die Rotationsenergie über dieselbe elektrische Maschine wieder in elektrische Energie rückwandelt.

Um die am besten geeignete Technologie für die mobile Power-Tank Anwendung zu finden, müssen die Vor- und Nachteile der drei Speicherprinzipien gegeneinander abgewogen werden. Ein Optimum zwischen maximaler gravimetrischer und volumetrischer Energie- und Leistungsdichte, minimaler Verlustleistung im Speicher und kleinstmöglichen Kosten ist zu finden. Ein „Ragone-Diagramm“ (siehe Abb. 6), das in einem doppelt logarithmischen Maßstab die Energiedichte bezogen auf die Leistungsdichte darstellt, kann dazu unter Beachtung gewisser Randbedingungen herangezogen werden. 
Die folgende Abb. 6 basiert auf den Datenblättern der Firmen: A123, Skeleton Technologies, Yunasko, Saft, Altair Nano, Panasonic, Sanyo, Kokam, Varta, Wima, Epcos, Nesscap, Maxwell, Compact Dynamics, Williams Hybrid Power und CCM.

Das Verhältnis von Energie zu Leistung ist die Zeit, um den Speicher vollständig aufzuladen respektive zu entladen. Typischerweise ist dies in diagonalen Isochronen dargestellt. Jedoch enthält das in der Literatur typisch verwendete Ragone-Diagramm keine Informationen über den Wirkungsgrad eines Speichers und damit, ob der Speicher die thermische Belastung einer vollständigen Ladung oder Entladung ohne Schaden in der durch die Isochrone angegebenen Zeit aushält.

Hersteller neigen dazu, ihr Produkt möglichst attraktiv darzustellen und geben daher manchmal in den Spezifikationen des Speichers die Maximalwerte der Leistungsdichte und der Energiedichte an. Bei der Energiedichtebestimmung wird der Speicher mit geringer Last entladen, da dann der entnehmbare Energieinhalt maximiert ist und die im Speicher anfallende Verlustleistung und damit die Erwärmung des Speichers vernachlässigt werden kann. Bei der Leistungsdichtebestimmung gehen manche Hersteller sogar bis an die „Leistungsanpassung“ der Last an die Quelle, bei der grundsätzlich die maximal mögliche Leistung aus der Quelle (dem Power-Tank) entnommen wird. Allerdings entsteht bei dieser Betriebsart im Speicher gleich viel Verlustleistung wie Nutzleistung in der Last verbraucht wird. Naturgemäß können nur wenige Prozent Energie (DOD sehr klein) aus dem Speicher entnommen werden, da sonst die Eigenerwärmung zur sofortigen Zerstörung des Speichers führen würde. Da das Ragone-Diagramm für die Energiebestimmung keine Angaben zur CRate und für die Leistungsmessung zum DOD macht, können die in Ragone-Diagrammen eingetragenen Werte irreführend sein, außer es wird vom Autor zusätzlich die Messmethode für die Energie- und Leistungsmessung des jeweiligen Speichers offengelegt.

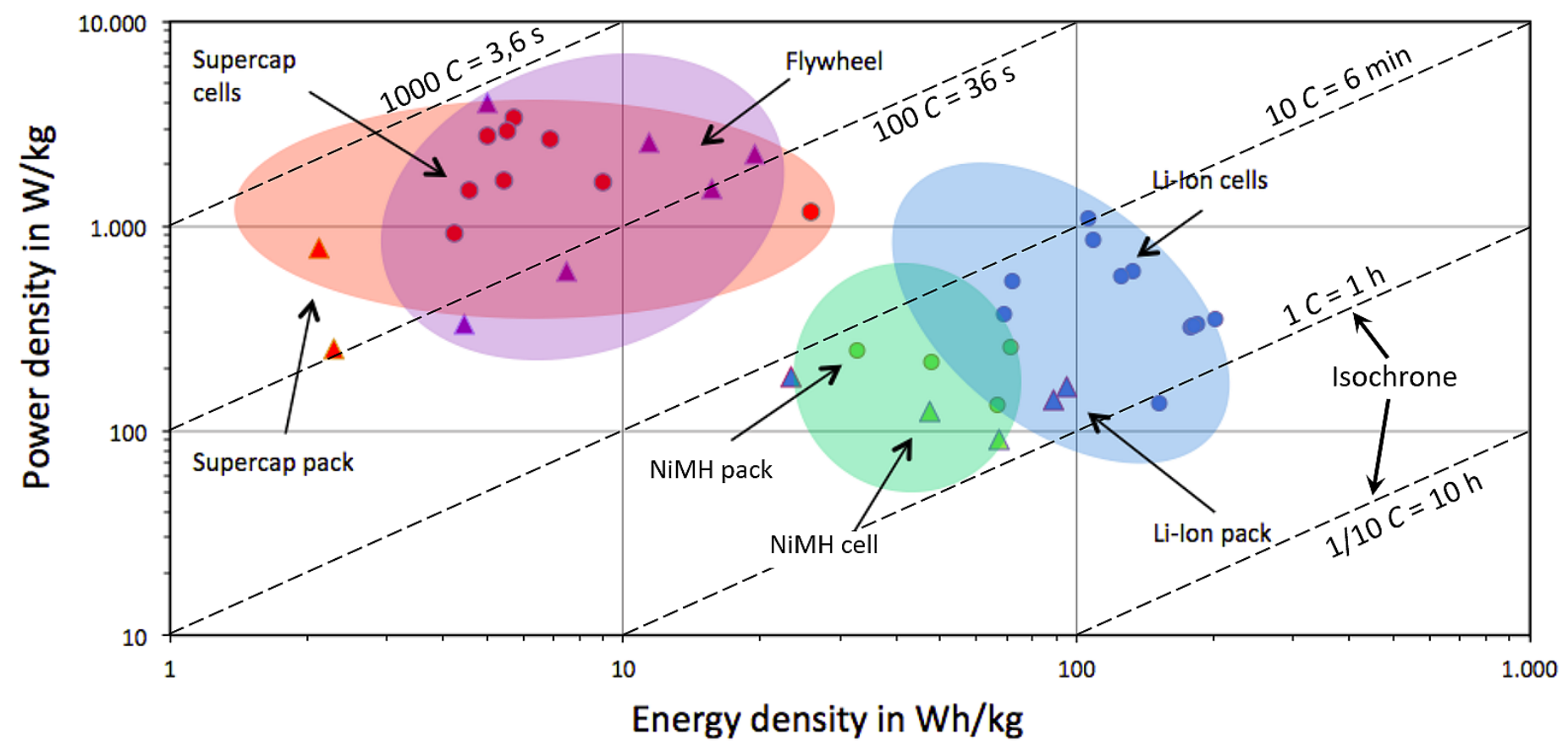

Abb. 6: Gravimetrisches Ragone-Diagramm bei $\mathbf{9 0} \%$ Wirkungsgrad der Speicher (basierend auf [35]); blau: Lithium-Ionen, grün: Nickel-Metallhydrid und orange: Supercapacitor Zellen und Module; lila: Schwungradspeicher 
Um in Abb. 6 einen korrekten Vergleich zu ermöglichen, sind alle Daten der Speicher bei einer Effizienz von 90 \% eingetragen. Damit ist die Verlustleistung jedes Speichers so gering (10\%), dass der Speicher bei geeigneter Kühlung mit der angegebenen Leistungsdichte vollständig geoder entladen werden kann.

Schwungräder und kommerziell erhältliche Module sind in Abb. 6 als Dreiecke markiert, die Leistungswerte einzelner Zellen sind als Kreise dargestellt. Werte von Einzelzellen sind theoretische Werte, da zum Aufbau des kompletten Power-Tanks zusätzlich zu den Einzelzellen auch Zellverbinder, Kühlkanäle, Gehäuse und Überwachungselektronik für die Zellbalancierung und das Batteriemanagementsystem erforderlich sind.

\subsection{Speicherauswahl unter Berücksichtigung der Lastkollektive aus Fahrzyklen}

Das Konzept eines verbrauchsoptimierten Hybridfahrzeuges mit einem leistungsfähigen Power-Tank, löst den für Vkm-Fahrzeuge unlösbaren Zielkonflikt, sehr gute Verbrauchs- und Emissionswerte und GLEICHZEITIG agile, sportliche Fahrleistungen zu bieten. Die drei vom Fahrzeughersteller festzulegenden Randbedingungen sind:

1) Größte, permanent fahrbare Durchschnittsgeschwindigkeit: sie wird durch die Leistung $P_{\mathrm{FC}}$ des Fuel-Converter (siehe Kapitel 7 ) bestimmt.

2) Höchstgeschwindigkeit und/oder maximale Beschleunigung: sie wird durch die Maximalleistung $P_{\max }$ des Power-Tanks und die Anzahl der zulässigen Lade/Entladezyklen festgelegt (siehe Kapitel 9 und Tabelle 2).

3) Zeit, die das Fahrzeug mit der Höchstgeschwindigkeit fahren kann: sie wird durch den nutzbaren Energieinhalt $W_{75}$ des Power-Tanks (siehe Kapitel 9 und Tabelle 2) definiert.

\subsubsection{Realisierung eines Power-Tanks mit Batterien}

Bis auf eine Ausnahme sind die hohe C-Raten Anforderung an einen Power-Tank in Kombination mit einer hohen (> 10.000 bei $75 \%$ DOD) Zyklenzahl mit keiner heute erhältlichen Batterietechnologie erzielbar. Die Ausnahme sind möglicherweise Lithium-Titanat Batterien. Diese sind eine Ausführung einer Lithium-Ionen Batterie, bei der die negative Graphit Elektrode (Anode) durch eine gesinterte Elektrode aus Lithiumtitanspinell $\left(\mathrm{Li}_{4} \mathrm{Ti}_{5} \mathrm{O}_{12}\right)$ ersetzt ist. Da das Titanat nicht mit Oxiden aus der negativen Elektrode (Kathode) reagieren kann, wird bei dieser Bauform selbst bei mechanischen Schäden das thermische Durchgehen (thermal runaway) des Akkumulators verhindert. Diese Batterie kann in einem Temperaturbereich von $-40{ }^{\circ} \mathrm{C}$ bis $+55^{\circ} \mathrm{C}$ betrieben werden. Nachteilig ist die zum Vergleich zu LithiumIonen Batterien mit Graphit Anode geringere Leerlaufspannung von ca. 2,4 V, die zu einer geringeren Energiedichte von $30 \mathrm{Wh} / \mathrm{kg}$ bis $110 \mathrm{Wh} / \mathrm{kg}$ führt [10] und [36]. Ein weiterer Nachteil ist der hohe Herstellungspreis (Stand 2016), der eine breite Markteinführung erschwert [36]. Die C-Raten für Dauerladen und -entladen (mehrere Minuten), insbesondere Aufladen bei niederen Temperaturen (bei $-20^{\circ} \mathrm{C}$ sind nur $1 \mathrm{C}$ Lade-/Entladerate zugelassen) und Zyklenzahl bei $C$-Raten von $20 C$ und darüber werden vom Hersteller nicht veröffentlicht und dürften noch Verbesserungspotenzial haben.

Die Eigenschaften der Lithiumtitanat-Batteriezelle von Toshiba (10 Ah SCiB ${ }^{\mathrm{TM}}$ ) oder der Kokam (SLPB130255255N_X60) eignen sich möglicherweise für den Power Tank. Maximal 20 C sind für $80 \%$ DOD Laden / Entladen innerhalb von 3 Minuten zugelassen. Das entspricht einer Lade- / Entladeleistung $P_{\mathrm{c} / \mathrm{d}}=2,4 \mathrm{~V} \cdot 200 \mathrm{~A}=480 \mathrm{~W}$. Dabei entsteht in jeder Zelle eine Verlustleistung $P_{\mathrm{vc}}$ von ca. $30 \mathrm{~W}$ (siehe Abb. 5). 
Tabelle 4 Spezifikationen von Ultra High Power Lithium Polymer (NMC) und Lithium-TitanOxyd (LTO) Batterien.

\begin{tabular}{|l|c|c|c|c|c|c|c|c|c|c|}
\hline & Type & $\begin{array}{c}\text { C-Rate } \\
\text { Laden } \\
\text { Dauer }\end{array}$ & $\begin{array}{c}\text { C-Rate } \\
\text { Laden } \\
\text { Puls 10s }\end{array}$ & $\begin{array}{c}\text { C-Rate } \\
\text { Entladen } \\
\text { Dauer }\end{array}$ & $\begin{array}{c}\text { C-Rate } \\
\text { Entladen } \\
\text { Puls 10s }\end{array}$ & $\begin{array}{c}\text { Kapazität } \\
\text { Ah }\end{array}$ & $\begin{array}{c}\text { Span- } \\
\text { nung } \\
\text { V }\end{array}$ & $\begin{array}{c}\text { Energie } \\
\text { Wh/kg }\end{array}$ & Verluste & $\begin{array}{c}\text { Zyklen } \\
\text { Zahl }\end{array}$ \\
\hline $\begin{array}{l}\text { Toshiba [10] } \\
\text { LTO }\end{array}$ & SCiB 10 Ah & 20 & 62,5 & 20 & 75 & 10 & 2,4 & 47 & $\begin{array}{c}\text { Siehe } \\
\text { Abb. 5 }\end{array}$ & $\begin{array}{c}20.000 @ \\
5 C\end{array}$ \\
\hline $\begin{array}{l}\text { Kokam [7] } \\
\text { NMC }\end{array}$ & $\begin{array}{l}\text { SLPB98188 } \\
\text { 216 P }\end{array}$ & 4 & & 20 & 30 & 30 & 3,7 & 128 & $1 \mathrm{~m} \Omega$ & $\begin{array}{c}4.000 \\
@ ~ 4 C\end{array}$ \\
\hline $\begin{array}{l}\text { Kokam [7] } \\
\text { LTO }\end{array}$ & $\begin{array}{l}\text { SLPB13025 } \\
\text { 5255N_X60 }\end{array}$ & 4 & 8 & 6 & 10 & 60 & 2,4 & 76 & $0,40 \mathrm{~m} \Omega$ & $\begin{array}{c}20.000 \\
@ 1 C\end{array}$ \\
\hline
\end{tabular}

Das verbrauchsoptimierte Fahrzeug hat laut Tabelle 3 einen Power-Tank Energieinhalt von $\underline{W_{\mathrm{PT}}}=4,09 \mathrm{kWh}$ und eine Maximalleistung von $\underline{P}_{\max }=80 \mathrm{~kW}$. Die gewünschte Power-Tank Energie lässt sich unter Einhaltung der maximal spezifizierten $20 C$ Dauerlade- / entladerate mit 167 Batteriezellen à 24 Wh der SCiB 10 Ah Zelle von Toshiba [10] erzielen (20 C = 200 A $\rightarrow$ $200 \mathrm{~A} \cdot 2,4 \mathrm{~V}=P_{\mathrm{c} / \mathrm{d}}=480 \mathrm{~W}$ pro Zelle $\left.\rightarrow B_{\mathrm{P}}=P_{\mathrm{PT}} / P_{\mathrm{c} / \mathrm{d}}=80.000 / 480=167\right)$. Die Batteriekühlung muss bei $20 C$ Dauerlade- / entladerate sicherstellen, dass auch bei $5 \mathrm{~kW}$ Verlustleistung im Batteriepack ( $30 \mathrm{~W}$ pro Zelle, siehe Abb. 5) in keiner der 167 Zellen die Temperatur über die zulässige Maximaltemperatur von $55{ }^{\circ} \mathrm{C}$ ansteigt. Diese Bedingung stellt hohe Anforderungen an das Batteriekühlsystem des Fahrzeuges.

Zur Erfüllung des Testzyklus (siehe Tabelle 2) aus Kapitel [10] hätte auch ein Power-Tank mit dem halben Energieinhalt $\underline{W}_{\mathrm{PT}}=2,02 \mathrm{kWh}$ ausgereicht, also mit nur 84 Batteriezellen des gleichen Typs à $24 \mathrm{Wh}(84 \cdot 24 \mathrm{Wh}=2,02 \mathrm{kWh})$. Allerdings wäre die maximal zulässige Leistung der eingesetzten Zellen mit $952 \mathrm{~W}$ pro Zelle (ca. $40 \mathrm{C}$ Lade- /-Entladerate) weit überschritten worden, womit diese Lösung verworfen werden musste.

Die größere 4,09 kWh Batterie führt durch das Mehrgewicht zu mehr Verbrauch und bewirkt, dass sich der Fuel-Converter nur etwa halb so oft einschalten wird als bei einem 2 kWh Pack.

\section{Lebensdauer der Batteriezellen}

Der Power-Tank muss laut Testzyklus etwa 10.000 Volladezyklen mit Spitzenleistungen gemäß Tabelle 3, die in 23,8\% der Zeit über den C-Raten liegt, die der Batteriehersteller für die Lebensdauerbestimmung festgelegt hat $(5 C)$. Der Hersteller garantiert für den gewählten Zelltyp Toshiba $10 \mathrm{Ah} \mathrm{SCiB}{ }^{\mathrm{TM}}$ bei $5 \mathrm{C}$ Lade-/Entladeströmen und $35^{\circ} \mathrm{C}$ Umgebungstemperatur nach 20.000 Zyklen eine maximale Abnahme der Kapazität um $10 \%$ [10]. Wie stark die Batterie beim Einsatz als Power-Tank zufolge der wesentlich größeren $C$-Raten altert, lässt sich nicht aus den öffentlich verfügbaren Herstellerangaben ermitteln und müsste über Experimente herausgefunden werden.

Für Lithium-Batterien mit Graphit Anode, die nur mit wesentlich kleineren C-Raten belastet werden dürfen, könnte man den Batteriespeicher soweit vergrößern, bis die $C$-Raten auf ca. $3 C$ bis $5 C$ reduziert sind. Beim Power-Tank des betrachteten Fahrzeugs würde dies eine Batterie mit vierfacher Kapazität, also $W_{\mathrm{PT}}=16 \mathrm{kWh}$, bedeuten. Fraglich bleibt, ob die vergrößerte Batterie einigen Tausend Lade- / Entladezyklen mit 75 \% DOD erfüllen kann. Das Gewicht, die Kosten und nicht zuletzt der Sicherheitsaspekt der vergrößerten Batterie sind ein signifikantes Manko für die Realisierung des Power-Tanks mit Hilfe von Lithium-lonen Batterien mit Graphit Anode. 


\subsubsection{Realisierung eines Power-Tanks mit Kondensatoren}

Aus Abb. 6 erkennt man, dass eine Supercapacitor Zelle mit ca. 25 Wh/kg im RagoneDiagramm eingetragen ist. Diese Prototypzelle erreicht die hohe Energiedichte durch die Integration einer Art Lithium-Ionen Batterietechnologie in die Zelle. Damit sinkt allerdings die hohe Zyklenfestigkeit von "standard" Supercapacitor Zellen auf deutlich unter die geforderten 10.000 Lade-Entladezyklen. Alle anderen in Abb. 6 eingetragenen Zellen haben Energiedichten unter $10 \mathrm{Wh} / \mathrm{kg}$, die sich beim Zusammenbau eines Moduls aus Einzelzellen auf ca. $4 \mathrm{Wh} / \mathrm{kg}$ reduzieren, da - wie bereits ausgeführt - zusätzliche Komponenten wie Zellverbinder, Gehäuse und viel Elektronik für die Zellbalancierung erforderlich sind. Den Mehraufwand erkennt man, wenn man Einzelzellen mit handelsüblichen Supercapacitor Modulen vergleicht, die nur ca. $2 \mathrm{Wh} / \mathrm{kg}$ bieten.

Ein genereller Nachteil von Supercapacitors ist, dass sich die Klemmenspannung des PowerTanks beim Entladen verringert, da der Energieinhalt eines Kondensators quadratisch mit der Kondensatorspannung abnimmt. Wenn man $75 \%$ der gespeicherten Energie entnehmen will, halbiert sich die Klemmenspannung des Power-Tank. Damit verdoppelt sich bei festgehaltener Leistung der Strom aus dem Speicher, wodurch sich die Ohm'schen Verluste vervierfachen. Die Realisierung eines Power-Tanks mit Supercapacitors ist aber grundsätzlich möglich, da die Zyklenfestigkeit und die Leistungsdichte der Zellen für den Anwendungsfall ausreichend sind. Die Kühlung eines mit Supercapacitors realisierten Power-Tanks sollte kein unüberwind bares Problem darstellen, da der Einsatztemperaturbereich der Zellen typisch von -40 bis $+70^{\circ} \mathrm{C}$ spezifiziert ist. Basierend auf einer optimistisch angenommenen Energiedichte von $5 \mathrm{Wh} / \mathrm{kg}$ wäre das Gewicht eines $4 \mathrm{kWh}$ Power-Tanks für das verbrauchsoptimierte Fahrzeug $\underline{800 \mathrm{~kg}}$ und damit kaum praxistauglich.

\subsubsection{Realisierung eines Power-Tanks mit einem Schwungrad}

Abb. 6 zeigt, dass Schwungräder eine vergleichbare gravimetrische Leistungsdichte wie Supercapacitor Zellen haben. Wenn man aber den oben angenommenen Faktor 2 zwischen Zellebene und Modulebene in Betracht zieht, haben Schwungräder einen klaren Vorteil. Im Vergleich zu Batterien zeigen Schwungräder etwa die Hälfte der gravimetrischen Energiedichte von NiMH-Modulen, etwa ein Zehntel der spezifischen Energie von Lithium-basierten Zellen und etwa 20 bis $30 \%$ der Energie von Lithium-Titanat Batterien.

Darüber hinaus bieten Schwungräder eine Reihe von Vorteilen, wie einen großen Bereich der Betriebstemperatur, eine hohe Zyklenfestigkeit, Tiefentladung und daher eine längere Lebensdauer als Supercapacitors oder Batterien sowie eine Recyclingfähigkeit von bis zu 100 Prozent. Dies spielt eine wichtige Rolle in der Lebenszyklusbewertung eines Speichersystems.

Die gravimetrische Leistungsdichte eines Schwungrades beträgt laut Abb. 6 ca. $2 \mathrm{~kW} / \mathrm{kg}$ und laut [37] 2,2 kW/kg und die gravimetrische Energiedichte ca. $20 \mathrm{Wh} / \mathrm{kg}$. Das bedeutet für das verbrauchsoptimierte Fahrzeug mit einer Maximalleistung $P_{\max }=80 \mathrm{~kW}$ des Power-Tanks ein Gewicht des Schwungradspeichers von $40 \mathrm{~kg}(2 \mathrm{~kW} / \mathrm{kg} \cdot 40 \mathrm{~kg}=80 \mathrm{~kW})$. Wenn man das Gewicht des Schwungradspeichers aus der gravimetrischen Energiedichte von $20 \mathrm{Wh} / \mathrm{kg}$ (siehe Abb. 6) bestimmt, resultiert ein Gewicht von $200 \mathrm{~kg}(20 \mathrm{kWh} / \mathrm{kg} \cdot 200 \mathrm{~kg}=4 \mathrm{kWh})$. Da sich der Testzyklus aus Tabelle 2 bei etwa einer Verdopplung der Zyklenzahl auch mit $2 \mathrm{kWh}$ Energieinhalt darstellen lässt, käme auch ein Schwungradspeicher mit etwa 100 kg Gewicht in Frage. Die Maximalleistung $P_{\max }=80 \mathrm{~kW}$ des Power-Tanks und damit auch die Kühlung des Schwungradspeichers sind bei diesem Energieinhalt gut zu bewerkstelligen. 


\section{Simulation des elektrischen Antriebstranges im Artemis-Zyklus}

Kapitel 9 hat bereits die Leistungsfähigkeit und den geringen Kraftstoffverbrauch eines Hybridfahrzeuges mit Fuel-Converter und Power-Tank in einem speziellen HochleistungsTestzyklus gezeigt. Im Folgenden werden der Kraftstoffverbrauch und die Power-Tank Belastung dieses Hybridfahrzeuges anhand eines standardisierten Verbrauchszyklus ermittelt, mit einem konventionellen Vkm Fahrzeug mit ähnlicher Leistung, Gewicht und Luftwiderstand und mit einem um $400 \mathrm{~kg}$ schwereren BEV mit ähnlicher Leistung und Luftwiderstand verglichen.

\section{Als Basis der Simulation dient:}

- das in Kapitel 5 vorgestellte Mittelklassefahrzeuge (Mercedes Benz E 200, Rollwiderstandsbeiwert $\mu=0,013$ und Luftwiderstand $c_{w} \cdot A=0,60$ ),

- der in Kapitel 10.2.1 erarbeite Power-Tank mit einer Lithium-Titanat Batterie mit einem Energieinhalt $W_{\mathrm{PT}}=4,09 \mathrm{kWh}$, einer Maximalleistung $P_{\max }=80 \mathrm{~kW}$ und einem aus dem jeweiligen Zyklus bestimmten Round-trip Wirkungsgrad $\eta_{\mathrm{PT}}$ des Batteriepacks und

- ein im Fahrzeug verwendeter elektrischer Antriebsstrang, der aus einem Umrichter mit einer elektrischen Antriebsmaschine mit mechanischer Kopplung zu den Antriebsrädern besteht. Die Simulation berücksichtigt den lastabhängigen Wirkungsgrad des Antriebstranges gemäß dem Wirkungsgradkennfeld aus Abb. 7.

- Der Fuel-Converter aus Kapitel 7 sorgt mit einer elektrischen Leistung von $P_{\mathrm{PT}}=35 \mathrm{~kW}$, dass der Ladezustand des Power-Tank zwischen 12,5\% und 87,5 \% (75 \% DOD) liegt. Er konvertiert die Kraftstoffenergie von Benzin oder Dieselkraftstoff, repräsentiert durch den Heizwert $H_{\cup}$, mit dem Konversionswirkungsgrad $\eta_{\Sigma}=54,87 \%$ zu elektrischer Energie (siehe die einfachere Variante 1 aus Abb. 3)

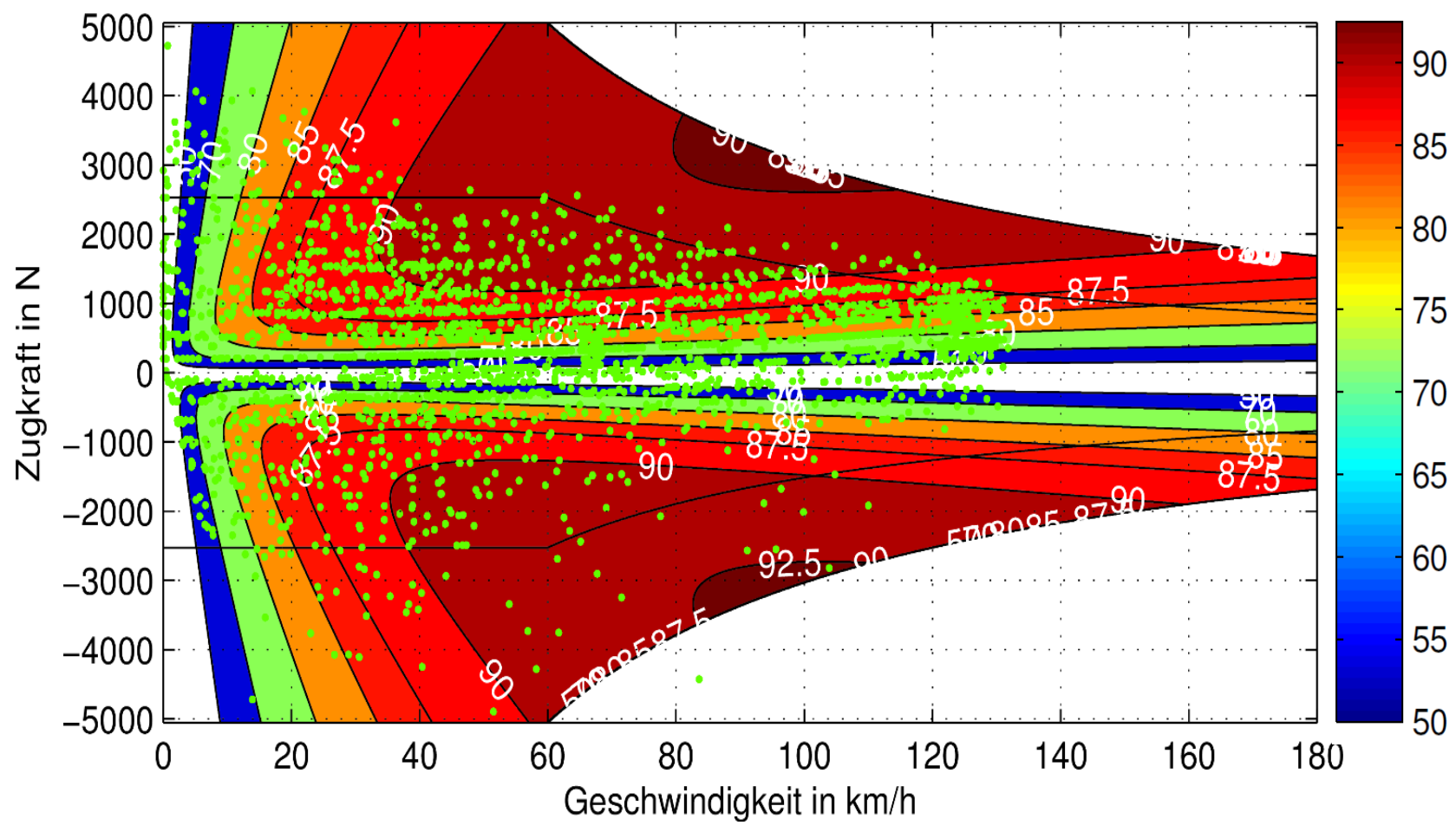

Abb. 7: Wirkungsgradkennfeld des elektrischen Antriebs (Umrichter + elektrische Maschine + Ankopplung zu den Antriebsrädern) im Artemis Zyklus. Die schwarze Linie ist der Bereich der Nennleistung (40 kW mechanische Leistung), das Kennfeld ist auf zweifache Überlast begrenzt ( $80 \mathrm{~kW})$. Die Grenzen der eingefärbten Flächen sind: 50; 70; $80 ; 85 ; 87,5 ; 90$ und 92,5\% Wirkungsgrad des elektrischen Antriebs. 
Zur Ermittlung des Kraftstoffverbrauches wird das Fahrzeug in einem Artemis-Zyklus (Abb. 8, Common Artemis Driving Cycle (CADC) [30]), der aus einem Stadt-, Überland- und Autobahnzyklus besteht, betrieben. Während der gesamten Testdauer versorgt der Power-Tank zusätzlich Nebenaggregate mit 2 kW elektrischer Leistung (Klimaanlage, Heizung, Licht, etc.).

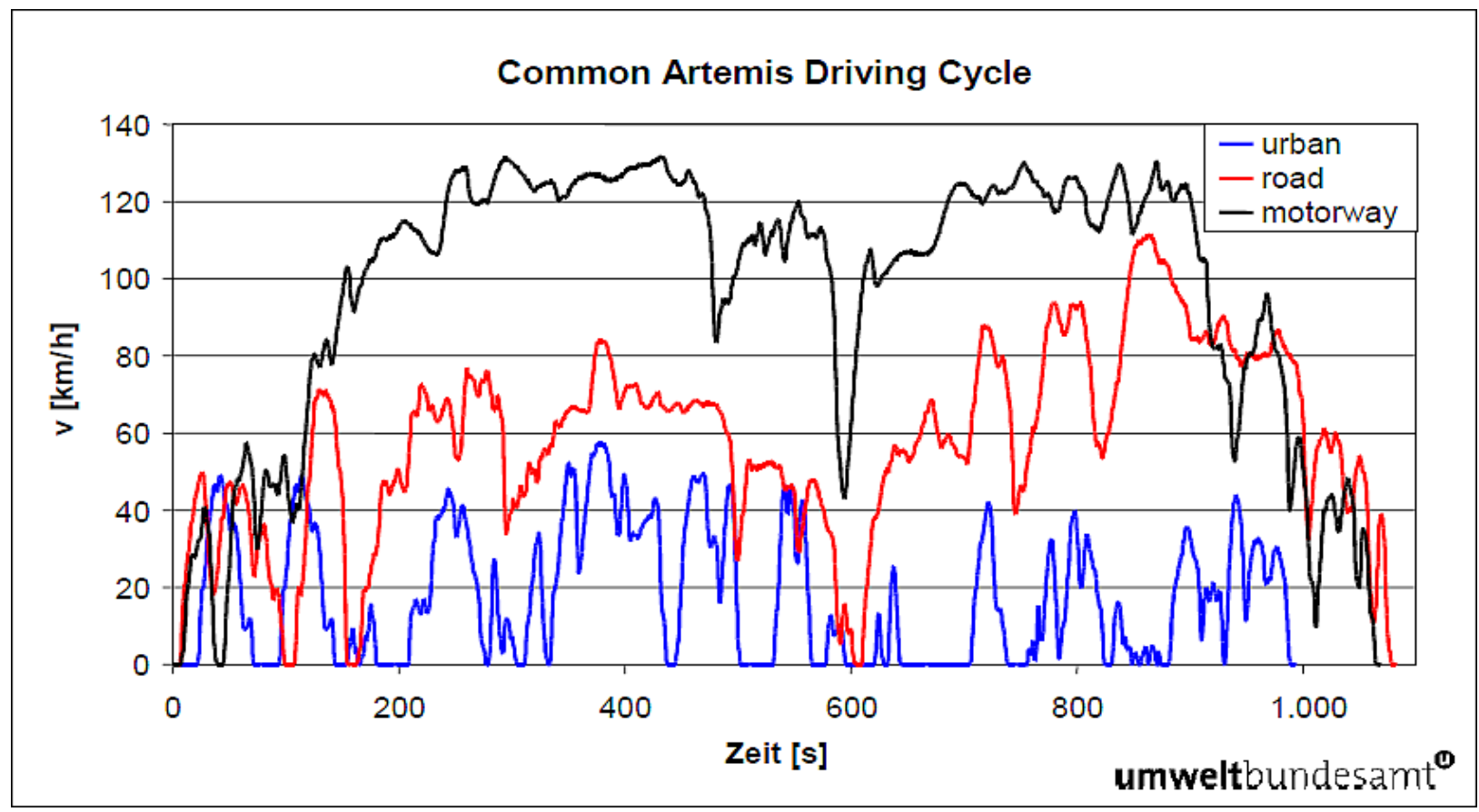

Abb. 8: Geschwindigkeitsverlauf des Common Artemis Driving Cycles, CADC, aus [30].

\subsection{Der Artemis Stadtzyklus}

Der Artemis „Urban-Cycle“ hat eine Streckenlänge von 4,9 km und benötigt 16,6 Minuten Fahrzeit, in der zusätzlich Nebenaggregate mit einer Leistung von $2 \mathrm{~kW}$ versorgt werden müssen. Die Durchschnittsgeschwindigkeit des in Abb. 8 ersichtlichen Geschwindigkeitsprofils beträgt $17,7 \mathrm{~km} / \mathrm{h}$. In diesem Fahrzyklus ist der mittlere Wirkungsgrad des elektrischen Antriebstranges motorisch wie generatorisch $84 \%$ und der Round-Trip Wirkungsgrad des Power-Tanks beträgt 96,8 \%. Die Abb. 9 und Abb. 10 zeigen Simulationsergebnisse.
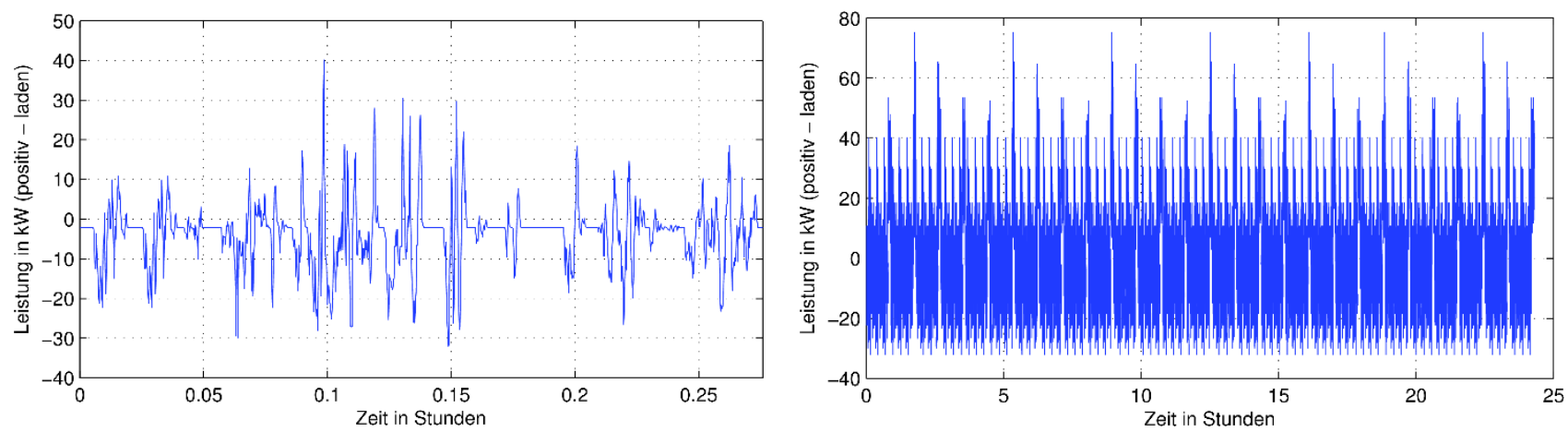

Abb. 9: Antriebsleistung in einem Urban-Cycle (links) und während 25 Stunden Fahrzeit. 

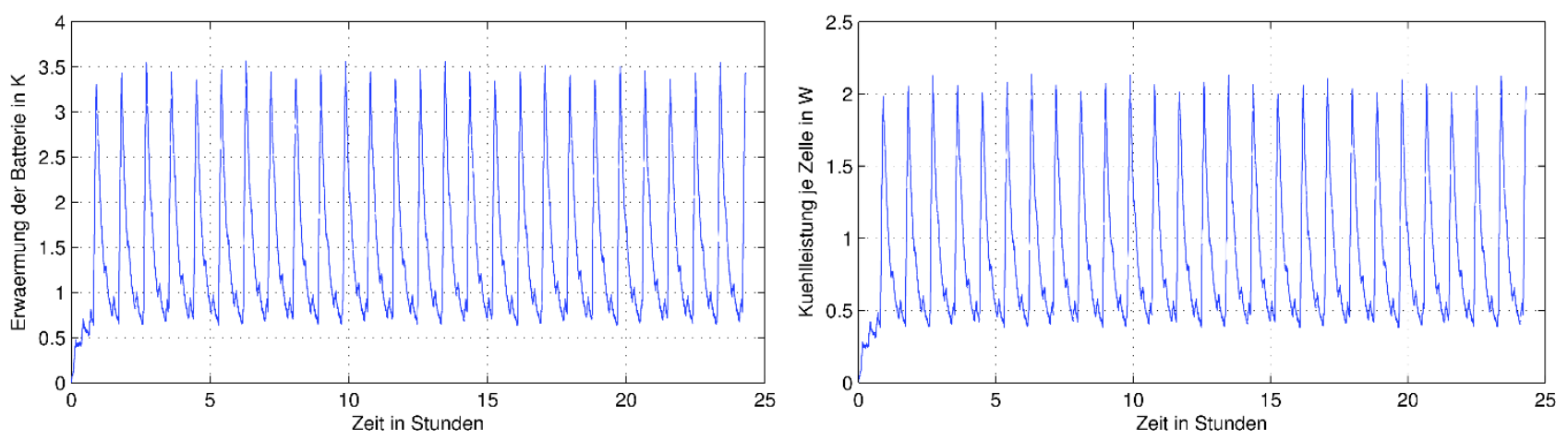

Abb. 10: Erwärmung (links) und Kühlleistung einer Batteriezelle während 25 Stunden Fahrzeit im Urban-Cycle.

Der Power-Tank versorgt den elektrischen Antriebsstrang und die Nebenaggregate mit elektrischer Energie. Zur Absolvierung des Artemis Urban-Cycle werden 10,8 kWh/100 km und zur Versorgung der Nebenaggregate weitere 11,3 kWh/100 km Energie benötigt; insgesamt $\mathbf{2 2 , 1} \mathbf{~ k W h / 1 0 0 ~ k m . ~ D e r ~ F u e l - C o n v e r t e r ~ k o n v e r t i e r t ~ d i e ~ K r a f t s t o f f e n e r g i e ~ m i t ~ e i n e m ~}$ Wirkungsgrad $\eta_{\Sigma}=54,87 \%$ in elektrische Energie und benötigt für die Versorgung des Antriebstrangs $\mathbf{2 , 0 1} \mathrm{l} / \mathbf{1 0 0} \mathrm{km}$ Dieselkraftstoff und für die Nebenaggregate zusätzlich 2,11 l/100 km Dieselkraftstoff, insgesamt 4,12 l/100 km Dieselkraftstoff.

\subsection{Der Artemis Überlandzyklus}

Das Geschwindigkeitsprofil des Road-Cycle ist in Abb. 8 ersichtlichen. Die Abb. 11 zeigt Simulationsergebnisse der Lade- und Entladeleistungen des Power-Tanks und die Abb. 12 die Erwärmung und die benötigte Kühlleistung einer Batteriezelle des Power-Tanks im Road-Cycle. Alle weiteren ermittelten Daten aus den drei Artemis Zyklen zum Antriebstrang, zum FuelConverter und zum Power-Tank sind in Tabelle 5 nach dem in Kapitel $\mathbf{1 1 . 3}$ vorgestellten Autobahnzyklus zusammengefasst.
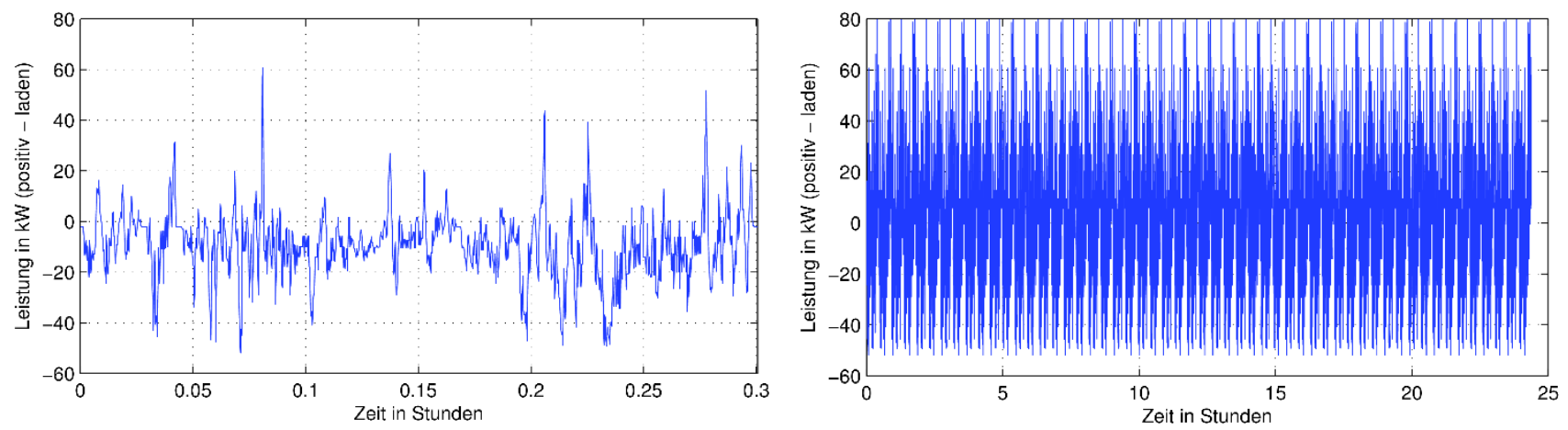

Abb. 11: Antriebsleistung in einem Road-Cycle (links) und während 25 Stunden Fahrzeit.
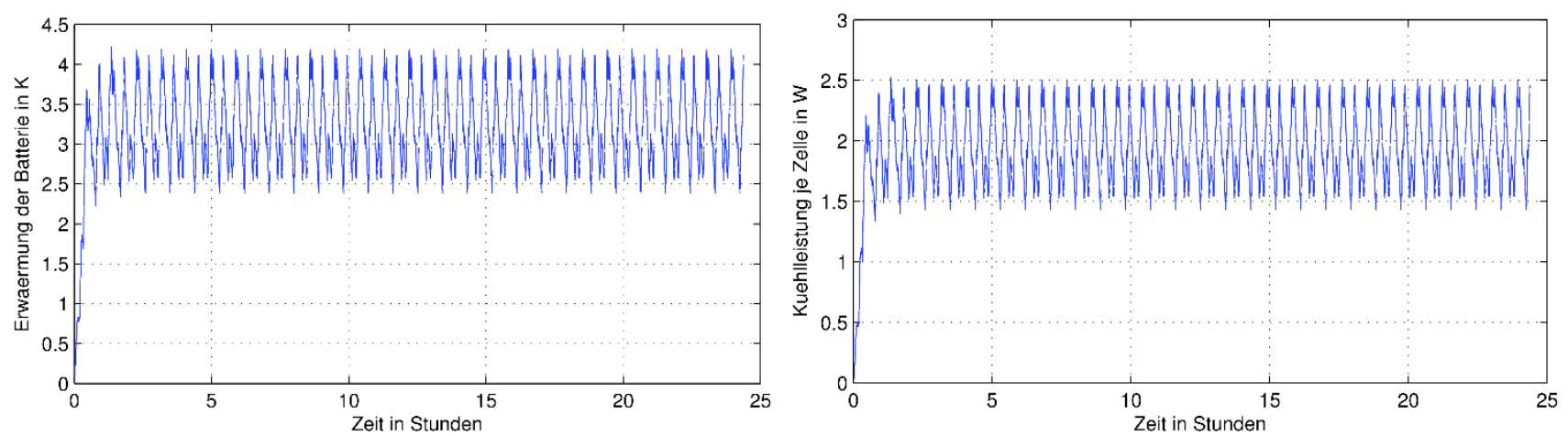

Abb. 12: Erwärmung (links) und Kühlleistung einer Batteriezelle während 25 Stunden Fahrzeit im Road-Cycle. 


\subsection{Der Artemis Autobahnzyklus}

Das Geschwindigkeitsprofil des Motorway-Cycle ist in Abb. 8 ersichtlichen. Die Abb. 13 zeigt Simulationsergebnisse der Lade- und Entladeleistungen des Power-Tanks und die Abb. 14 die Erwärmung und die benötigte Kühlleistung einer Batteriezelle des Power-Tanks im MotorwayCycle. Alle weiteren ermittelten Daten aus den drei Artemis Zyklen zum Antriebsstrang, zum Fuel-Converter und zum Power-Tank sind in Tabelle $\mathbf{5}$ nach dem in Kapitel $\mathbf{1 1 . 3}$ vorgestellten Autobahnzyklus zusammengefasst.
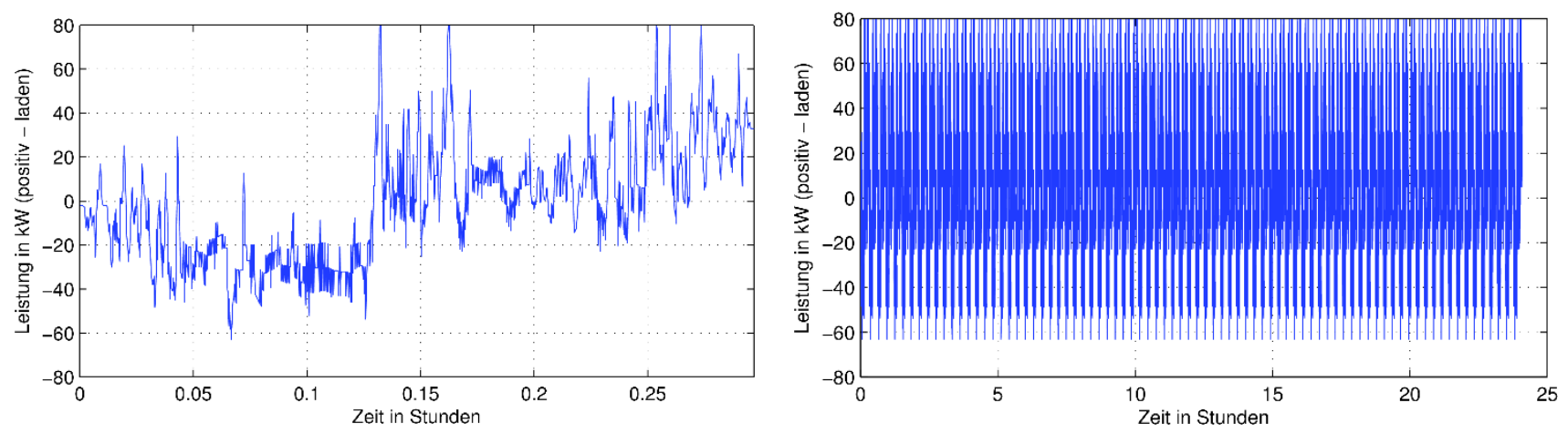

Abb. 13: Antriebsleistung in einem Motorway-Cycle (links) und während 25 Stunden Fahrzeit.
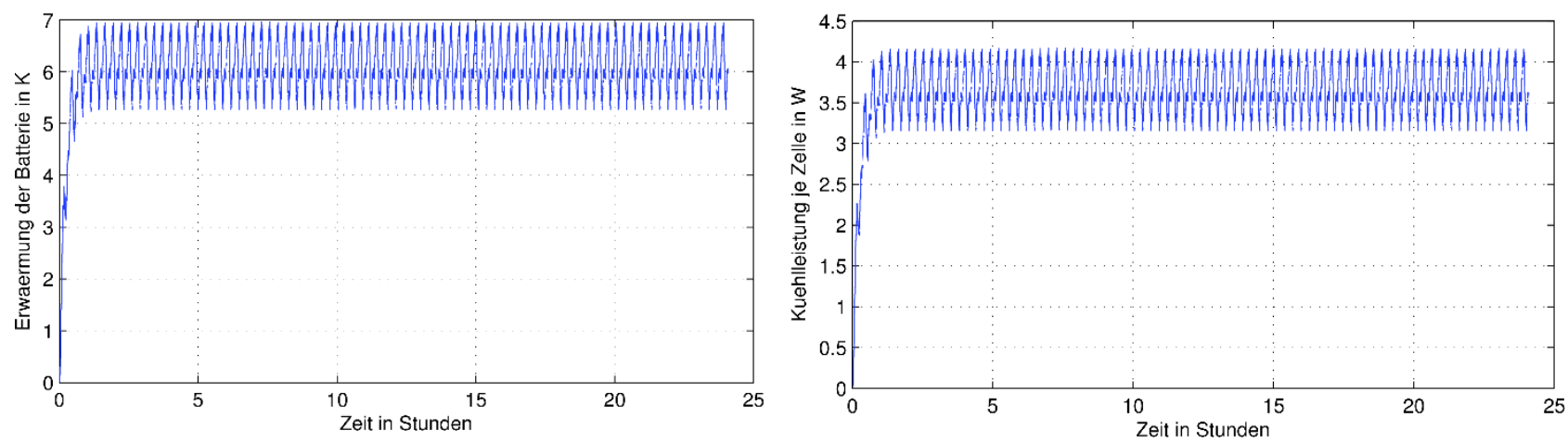

Abb. 14: Erwärmung (links) und Kühlleistung einer Batteriezelle während 25 Stunden Fahrzeit im Motorway-Cycle.

Tabelle 5 Zusammenfassung der ermittelten Daten im Common Artemis Driving Cycle gemäß Abb. 8

\begin{tabular}{|c|c|c|c|c|c|c|}
\hline \multirow{2}{*}{$\begin{array}{l}\text { Artemis } \\
\text { Zyklus }\end{array}$} & \multirow{2}{*}{$\begin{array}{l}\text { Strecken- } \\
\text { länge }\end{array}$} & \multirow{2}{*}{$\begin{array}{l}\text { Dauer } \\
\text { in Min. }\end{array}$} & \multirow{2}{*}{$\begin{array}{l}\text { Durchschnitts- } \\
\text { geschwindigkeit } \\
\text { aus Abb. } 8 \\
\end{array}$} & \multicolumn{2}{|c|}{$\begin{array}{l}\text { Wirkungsgrad des } \\
\text { Antriebsstranges: }\end{array}$} & \multirow{2}{*}{$\begin{array}{c}\text { Round-Trip } \\
\text { Wirkungsgrad des } \\
\text { Power-Tanks }\end{array}$} \\
\hline & & & & motorisch & generatorisch & \\
\hline Urban & $4,9 \mathrm{~km}$ & 16,6 & $17,7 \mathrm{~km} / \mathrm{h}$ & $84 \%$ & $84 \%$ & $96,6 \%$ \\
\hline Road & $17,3 \mathrm{~km}$ & 18,0 & $57,4 \mathrm{~km} / \mathrm{h}$ & $84,5 \%$ & $80 \%$ & $96,1 \%$ \\
\hline Motorway & $28,7 \mathrm{~km}$ & 17,8 & $96,8 \mathrm{~km} / \mathrm{h}$ & $84,1 \%$ & $81 \%$ & $94,9 \%$ \\
\hline
\end{tabular}




\begin{tabular}{|c|c|c|c|c|c|c|c|c|}
\hline \multirow{2}{*}{$\begin{array}{l}\text { Artemis } \\
\text { Zyklus }\end{array}$} & \multicolumn{3}{|c|}{$\begin{array}{l}\text { Der Power-Tank ( } 80 \% \text { DOD = 3,27 kWh) } \\
\text { liefert elektrische Energie in kWh } 100 \mathrm{~km} \text { zu }\end{array}$} & \multicolumn{3}{|c|}{$\begin{array}{l}\text { Fuel-Converter Wirkungsgrad = } 54,87 \% \\
\text { Dieselkraftstoffverbrauch in } 1 / 100 \mathrm{~km} \text { für }\end{array}$} & & \\
\hline & $\begin{array}{l}\text { Antriebs- } \\
\text { strang }\end{array}$ & $\begin{array}{l}\text { Nebenaggre- } \\
\text { gate mit } 2 \mathrm{~kW}\end{array}$ & Insgesamt & $\begin{array}{l}\text { Antriebs- } \\
\text { strang }\end{array}$ & $\begin{array}{l}\text { Nebenaggre- } \\
\text { gate mit } 2 \mathrm{~kW} \\
\end{array}$ & Insgesamt & & \\
\hline Urban & 10,8 & 11,3 & 22,1 & 2,01 & 2,22 & 4,12 & 14,8 & 200 \\
\hline Road & 13,4 & 3,5 & 16,9 & 2,5 & 0,65 & 3,15 & 19,3 & 334 \\
\hline Motorway & 20,3 & 2,1 & 22,4 & 3,78 & 0,39 & 4,17 & 14,6 & 618 \\
\hline \multicolumn{8}{|c|}{ Rein elektrische Betriebsstrecke im jeweiligen Zyklus bei $80 \%$ DOD des Power-Tanks in km: $\uparrow$} & \\
\hline
\end{tabular}

Zum Abschluss dieses Kapitels sind in Tabelle 6 der Kraftstoffverbrauch und die $\mathrm{CO}_{2}$ Emissionen im Artemis CADC Fahrzyklus des präsentierten Hybridfahrzeuges (siehe Abb. 1) mit einem konventionellen Pkw mit Vkm [39] und mit einem reinen batterieelektrischen Fahrzeug (BEV) verglichen. Das BEV ist baugleich mit dem Hybridfahrzeug und verwendet an Stelle des FuelConverter und des Power-Tanks (- $200 \mathrm{~kg}$ ) eine Hochenergiebatterie mit $600 \mathrm{~kg}$ Batteriepackmasse (1042 Kokam High Energy NMC Zellen: Type SLPB080085270, 27 Ah, 260 Wh/kg [7]). Damit steigt die Fahrzeugmasse des Hybridfahrzeuges von $1.500 \mathrm{~kg}$ auf $1.900 \mathrm{~kg}$. Die $\mathrm{CO}_{2}$ Emissionen der verglichenen Kraftstoffe sind auf Well-to-Wheel Basis angegeben. Beim Hybridfahrzeug sind sowohl die $\mathrm{CO}_{2}$ Emissionen bei reiner Kraftstoffbetankung angeführt als auch bei Betrieb des um $400 \mathrm{~kg}$ schwereren BEV, bei dem die elektrische Energie aus dem Netz mit vier verschiedenen Netzwirkungsgraden nachgeladen wird. Der Vergleich in Tabelle 6 zeigt, dass beim BEV zufolge der um $400 \mathrm{~kg}$ vergrößerten Batterie der Energieverbrauch gegenüber der Hybridlösung betriebsabhängig um ca. $6 \%$ bis $14 \%$ zunimmt.

Tabelle 6 zeigt, dass gegenüber einem Hybridfahrzeug mit Fuel-Converter ein konventionelles Fahrzeug mit Dieselmotor den Verbrauch und damit die $\mathrm{CO}_{2}$ Emissionen des Verkehrs signifikant erhöht (24 bis $80 \%$ ):

- Im Artemis „Urban Cycle“ verbraucht das dieselbetriebene Referenzfahrzeug um 80 \%,

- im „Road-Cycle“ um $37 \%$ und

- im „Motorway-Cycle“ um 24 \% mehr Kraftstoff als das Hybridfahrzeug.

Die $\mathrm{CO}_{2}$ Emissionen des konventionellen Fahrzeuges mit Dieselmotor erhöhen sich gegenüber dem Hybridfahrzeug um die gleichen Prozentsätze, da beide Fahrzeuge den gleichen Kraftstoff verwenden. Die Abgasnachbehandlung im Hybridfahrzeug gestaltet sich gegenüber dem Referenzfahrzeug einfacher, da der Fuel-Converter immer bei fixer Last und Drehzahl betrieben wird. 
Tabelle 7 Vergleich der $\mathrm{CO}_{2}$ Emissionen zum Laden eines $\mathrm{BEV}$ gegenüber einem dieselbetriebenen Hybridfahrzeug mit Fuel-Converter.

\begin{tabular}{|l|l|}
\hline Österreichisches Verbundnetz inkl. Importe 2018 & um 38 bis $44 \%$ weniger $\mathrm{CO}_{2}$ \\
\hline Europäisches Verbundnetz, Mittelwert 2013-2017 & um 5 bis $11 \%$ weniger $\mathrm{CO}_{2}$ \\
\hline Erdgas (fossiles Methan) & vergleichbar: -1 bis $+4 \%$ \\
\hline Globaler Energiemix (518 $\mathrm{g} \mathrm{CO}_{2} / \mathrm{kWh}$ ) [22] & um 23 bis $29 \% \mathrm{mehr} \mathrm{CO}_{2}$ \\
\hline Deutsches Verbundnetz 2016 & um 25 bis $31 \%$ mehr $\mathrm{CO}_{2}$ \\
\hline Steinkohle & um 112 bis $128 \%$ mehr $\mathrm{CO}_{2}$ \\
\hline Braunkohle & um 152 bis $172 \% \mathrm{mehr}^{\mathrm{CO}_{2}}$ \\
\hline
\end{tabular}

Für Österreich bedeutet dies wegen der Stellung als Stromimporteur, dass jede zusätzlich verbrauchte kWh Strom importiert werden muss und man einen sogenannten „Verdrängungsstrommix", der bis zu $800 \mathrm{~g} / \mathrm{kWh}$ betragen kann, erwartet, weil Kohlekraftwerke Gaskraftwerke vom Markt drängen. Damit bleiben Hybridfahrzeuge mit hohem Wirkungsgrad, also mit einem Fuel-Converter und Power-Tank, auch noch bis mindestens 2038 (Deutschlands Ausstieg aus der Kohleverstromung) ein Garant, die verkehrsbedingten $\mathrm{CO}_{2}$ Emissionen möglichst gering zu halten. Zusätzlich gewinnt die Volkswirtschaft Zeit, Mittel für die Schaffung einer flächendeckenden Schnellladeinfrastruktur für BEV oder Wasserstoff bereitzustellen, da weiterhin auf das bestehende Tankstellennetz mit flüssigen Kraftstoffen zurückgegriffen werden kann.

\section{Zusammenfassung}

Die technologische Facette einer nachhaltigen Elektromobilität muss Lösungsvorschläge anbieten, die langfristig die Mobilität der Bevölkerung sicherstellt und gleichzeitig die durch die Fahrzeuge hervorgerufenen Emissionen und den $\mathrm{CO}_{2}$ Ausstoß minimieren. Diese Lösungsvorschläge müssen wissenschaftlich untermauert, fair und für die Bevölkerung transparent dargestellt sein. Das impliziert nicht nur die Beachtung der durch den Betrieb der Fahrzeuge hervorgerufenen, sondern auch die durch die Erzeugung und die Entsorgung der Fahrzeuge entstehenden Schadstoffe und $\mathrm{CO}_{2}$ Emissionen; Stichwort "Life-Cycle-Assessment" (siehe Abb. 2).

Bis zum heutigen Tag ist die Verbrennungskraftmaschine DIE dominante Antriebsquelle für Mobilität, da sie zwei überzeugende Vorteile besitzt: Die Vkm kann die Antriebsenergie ohne Zwischenschritt direkt in Drehmoment zum Antrieb der Räder umwandeln und sie nutzt auf der ganzen Welt verfügbare flüssige Kraftstoffe, die eine unerreicht hohe gravimetrische wie volumetrische Energiedichte besitzen. Der Aufbau der heute verfügbaren Kraftstoffbereitstellungs- und Verteilinfrastruktur für Fahrzeuge hat gut 150 Jahre gedauert, hat Milliardenbeträge verschlungen und ist so gut wie in jedem Land der Welt vertreten. Diese Infrastruktur wäre quasi nutzlos und damit wertlos, wenn man bereits jetzt vollständig auf batterieelektrische Fahrzeuge umstiege, obwohl dadurch die globalen $\mathrm{CO}_{2}$ Emissionen kaum gesenkt würden.

Die Kapitel $\mathbf{3}$ und $\mathbf{4}$ zeigen auf, dass die scheinbar auf der Hand liegende Lösung eine nachhaltige Elektromobilität durch batterieelektrische Fahrzeuge aufzubauen, bereits zu Beginn des 20. Jahrhunderts gescheitert ist, da die Mitnahme der elektrischen Energie in ausreichender Menge und die rasche Aufladung damals wie heute ungelöst sind. Damit ist der Einsatz von batterieelektrischen Fahrzeugen nur in Städten oder Ballungsräumen sinnvoll, wo zufolge der geringen Geschwindigkeit der Fahrzeuge der Energieaufwand zur Zurücklegung einer Wegstrecke gering ist. Wenn man bei batterieelektrischen Fahrzeugen zusätzlich einen Power-Tank mit geringem Energieinhalt aber hoher Leistung einsetzt, kann man eine sehr 
gute Dynamik des elektrischen Antriebsstranges erreichen, eine nur mit geringen C-Raten belastbare dafür aber energieoptimierte Batterie einsetzen und zufolge der verringerten Zyklenzahl die Lebensdauer der Hochenergiebatterie steigern.

Kapitel $\mathbf{5}$ diskutiert zu Beginn die Problematik von Fahrzeugkonzepten, die sowohl in Städten als auch über Land den $\mathrm{CO}_{2}$ Ausstoß gegenüber konventionellen Fahrzeugen mit Vkm möglicherweise signifikant senken können. Leider bietet die Automobilindustrie gegenwärtig als eine Variante nur BEV mit großen schnellladefähigen Batterien am Markt an, die sowohl in Ballungsräumen wie über Land einsetzbar sind und zufolge des hohen Gewichtes und des bei weitem noch nicht $\mathrm{CO}_{2}$ freien Stromes keine signifikante Verbesserung der $\mathrm{CO}_{2}$ Emissionen des Verkehrs erreichen.

Die zweite am Markt befindliche Fahrzeugvariante zur $\mathrm{CO}_{2}$ Reduktion sind Hybridfahrzeuge, die neben dem elektrischen Antrieb auch eine leistungsstarke Vkm mit vielstufigem Automatikgetriebe einsetzen. Nur durch die Tatsache, dass im Test zur Festlegung der $\mathrm{CO}_{2}$ Emissionen des Fahrzeuges die für den Betrieb verwendete elektrische Energie mit Null $\mathrm{CO}_{2}$ Emissionen gewertet wird, zeigen diese Fahrzeuge am Papier eine Verringerung der $\mathrm{CO}_{2}$ Emissionen gegenüber konventionellen Fahrzeugen mit Vkm.

Anhand einer Fahrwiderstandskennlinie wird die für bestimmte Betriebszustände eines Mittelklasse-Pkws notwendig Antriebsleistung gezeigt und die Frage diskutiert, ob es nicht zur Gewichtsreduktion des Fahrzeuges sinnvoll wäre, die zum Betrieb notwendige elektrische Energie durch die Umwandlung von flüssigem Kraftstoff an Bord des Fahrzeuges mit einer besonders effizienten Vkm bereitzustellen, statt in einer zufolge hoher Kapazität schweren Batterie zu speichern.

Kapitel 6 diskutiert die $\mathrm{CO}_{2}$ Emissionen konventioneller und batterieelektrischer Fahrzeuge, da immer noch der Großteil der elektrischen Energie weltweit aus fossilen Quellen, insbesondere aus Kohle, gewonnen wird. Deutsche Kraftwerke erreichen im Mittel derzeit ca. $38 \%$ Wirkungsgrad und die im letzten Jahrzehnt ans Netz gegangenen neuen Kohlekraftwerke liegen zwischen 40 und $46 \%$ [20].

Die „Well-to-Wheel“ $\mathrm{CO}_{2}$ Emissionen von Fahrzeugen mit Verbrennungskraftmaschine (Vkm) und von batterieelektrischen Fahrzeugen (BEV), deren Primärenergie aus zum Teil fossilen Energieträgern stammt, unterscheiden sich nur wenig. Ein mit fossilen Kraftstoffen betriebener Kleinwagen ( $\mathrm{Vkm}$-Pkw) hat vergleichbare $\mathrm{CO}_{2}$ Emissionen wie ein Mittelklasseelektrofahrzeug (BEV), das mit Strom betrieben wird, der dem aktuellen globalen Energiemix entspricht und damit $518 \mathrm{~g} \mathrm{CO}_{2}$-eq/kWh aufweist. Bei Betrieb dieses BEV in Kanada, Brasilien, Frankreich oder Norwegen wären die $\mathrm{CO}_{2}$ Emissionen deutlich geringer (viel Strom aus Wasserkraft oder Kernenergie) und bei Betrieb in China, Südafrika oder Indien (vorwiegend Strom aus Kohle) deutlich höher.

Um das so wichtige Ziel, den $\mathrm{CO}_{2}$-Footprint des Verkehrs in absehbarer Zeit signifikant abzusenken, sind Elektrofahrzeuge schlecht geeignet, da der Umstieg der Stromerzeugung ein wesentlich langwieriger (mehrere Jahrzehnte) und kostspieligerer Prozess ist, als den Wirkungsgrad von Fahrzeugen, die mit Benzin oder Dieselkraftstoff betrieben werden, signifikant zu steigern. Hybridfahrzeuge mit Fuel-Converter und Power-Tank können nicht nur in industrialisierten Ländern, sondern insbesondere in den rasch wachsenden Schwellenländern, deren Bevölkerungszahlen explodieren und deren Wohlstand und damit Bedarf nach Mobilität wächst, eine Halbierung der realen, verkehrsbedingten $\mathrm{CO}_{2}$ Emissionen innerhalb von weniger als 10 Jahren erzielen. Weiters ist die signifikante Reduktion der verkehrsbedingten $\mathrm{CO}_{2}$ Emissionen in den Schwellenländern NICHT vom Aufbau einer Infrastruktur für neue Energieträger („grüner“ Strom oder Wasserstoff) abhängig. Der Infrastrukturaufbau benötigt 
hohe Finanzmittel und insbesondere gut ausgebildete Fachkräfte, die in Schwellenländern (noch) nicht zur Verfügung stehen.

Kapitel 7 bringt Beispiele, mit welchem Wirkungsgrad heutige Verbrennungskraftmaschinen flüssige Kraftstoffe in mechanische Arbeit umwandeln können. Durch die hohen dynamischen Anforderungen an moderne Fahrzeuge, muss die Vkm über ein weites Kennlinienfeld betrieben werden, woraus eine große Variationsbreite des Wirkungsgrades resultiert. Es wird in diesem Kapitel ein neuartiges Antriebskonzept vorgestellt, das unter Beibehaltung einer Vkm als primäre Leistungsquelle einen Systemwirkungsgrad von 55 bis $58 \%$ erreicht. Die Kernpunkte der Innovation sind der Betrieb der Vkm in einem optimierten Arbeitspunkt bei fixer Last und Drehzahl sowie die Umwandlung der dabei anfallenden Abgasenergie in elektrische Energie mit Hilfe von Abgasenergierückgewinnung (Waste-Heat-Recovery). Die Vkm wird in diesem Fall zum „Fuel-Converter" und dient ausschließlich dazu, einen elektrischen Hochleistungsspeicher, den Power-Tank, mit konstanter Leistung nachzuladen, wenn die Energie im Speicher zur Neige geht. Die elektrische Leistung des Fuel-Converters legt nur die Dauerhöchstgeschwindigkeit des Fahrzeuges fest und die Tankgröße die Reichweite.

Der hervorragende Gesamtwirkungsgrad eines Fuel-Converters von über $50 \%$ und die daraus ableitbare geringe $\mathrm{CO}_{2}$ Belastung von Hybridfahrzeugen mit Fuel-Converter sollten als Messlatte dienen, wie hoch die $\mathrm{CO}_{2}$ Belastung für die Bereitstellung der elektrischen Energie in einem Land maximal sein darf, damit ein Staat Förderungen für batterieelektrische Fahrzeuge vergibt.

Kapitel 8 diskutiert die grundsätzlichen Realisierungsvarianten für einen Power-Tank, also für einen elektrischen Energiespeicher mit hoher Leistung aber mit geringem Energieinhalt. Der Power-Tank versorgt den elektrischen Antriebsstrang des Fahrzeuges und garantiert zufolge der hohen Leistung, die er aufnehmen und abgeben kann, hervorragende Fahrdynamik. Der Energieinhalt des Power-Tanks legt fest, wie häufig der Fuel-Converter anspringen muss, damit der Power-Tank für den aktuellen Fahrbetrieb immer ausreichend aufgeladen ist.

Kapitel $\mathbf{9}$ erarbeitet an Hand eines mit einem Fuel-Converter und einem Power-Tank ausgerüsteten Fahrzeuges einen neuen Fahrzyklus, um Lastkollektive für den Power-Tank zu ermitteln, die diesen maximal belasten. Um die Technologiegrenzen auszuloten, ist der Fahrzyklus so gestaltet, dass der Power-Tank möglichst lange mit möglichst hoher Leistung betrieben werden muss. Die über Simulation erarbeitete Dimensionierungsvariante wird diskutiert, um für die darauf aufbauenden Simulationen von standardisierten Fahrzyklen eine ausreichend belastbare und in Kundenhand sichere und langlebige Variante des Power Tanks zu erhalten.

Kapitel 10 nutzt das im Kapitel 8 erarbeitete Lastkollektiv, um mit Hilfe eines RagoneDiagramms abzuleiten, welche der drei zur Verfügung stehenden Technologien, Supercapacitors, Batterien oder Schwungräder, für die Realisierung eines Power-Tanks am besten geeignet ist. Es stellt sich heraus, dass bis auf eine Ausnahme alle heute verfügbaren Batterietechnologien, die für gute Fahrdynamik notwendigen hohen Lade- und Entladeraten des Antriebstranges bereitzustellen, ungeeignet sind. Man muss die notwendige Power-Tank Kapazität vervielfachen, um dadurch zu kleineren $C$-Raten und geringeren Lade-/Entladetiefen der Batterie zu kommen, damit die Batterie weniger Verlustleistung produziert und die Zyklenzahl aushält. Die daraus resultierenden Mehrkosten und das Mehrgewicht sind hoch. Die erst vor wenigen Jahren auf den Markt gekommenen Lithium-Titanat Batterien könnten eine Option darstellen. Diese Ausführung einer Lithium-lonen Batterie ist für hohe Lade- und Entladeraten prädestiniert und verhindert zusätzlich das thermische Durchgehen des Akku- 
mulators. Ob die Zellen die zehntausenden Lade-/Entladezyklen innerhalb der Fahrzeuglebensdauer aushalten oder die Batterie einmal erneuert werden muss, ist noch im Experiment zu ermitteln. Verglichen mit „klassischen“ Lithium-Ionen Batterien, sind die deutlich geringere gravimetrische Energiedichte und die relativ hohen Kosten der Lithium-Titanat Batterie nachteilig.

Supercapacitors wären grundsätzlich als Power-Tank geeignet, scheiden aber auf Grund der zu geringen Energiedichte für die zu realisierende Energiemenge des Power-Tanks aus. Das Gewicht und die Kosten wären für Pkw Anwendungen viel zu hoch.

Schwungräder scheinen für die Applikation als Power-Tank gut geeignet, da sie in der Leistungsdichte mit Supercapacitors vergleichbar sind und die Energiedichte ausreicht, um eine nicht zu große Masse zu haben. Die zur Steigerung der Energiedichte höhere Festigkeit der Faserwerkstoffe ist ein Forschungsgebiet, das für viele Bereiche große Bedeutung hat. Davon können Schwungräder ohne viel Zutun profitieren und über am Markt verfügbare Faserwerkstoffe mit gesteigerter Festigkeit die gravimetrische Energiedichte der Schwungräder permanent steigern.

Kapitel 11 vergleicht den Kraftstoffverbrauch und die $\mathrm{CO}_{2}$ Emissionen von drei Fahrzeugen: eines konventionellen Fahrzeuges mit Vkm (Renault Megane), eines Hybridfahrzeuges mit Power-Tank und Fuel-Converter und das zum BEV umgerüstete Hybridfahrzeug im standardisierten Artemis Fahrzyklus. Es wird ausgeführt, warum das konventionelle dieselbetriebene Referenzfahrzeug im Artemis Fahrzyklus $32 \%$ bis $80 \%$ mehr $\mathrm{CO}_{2}$ emittiert als das mit gleichem Kraftstoff betriebene Hybridfahrzeug.

Der elektrische Antriebstrang des Hybridfahrzeuges benötigt elektrische Energie und diese kann entweder an Bord mit einem Fuel-Converter bei z.B. $55 \%$ Wirkungsgrad aus Dieselkraftstoff erzeugt werden oder aus einer Fahrzeugbatterie stammen, die über das öffentliche Netz nachgeladen wird. Damit legen die von der Primärenergie und dem Kraftwerkswirkungsgrad abhängigen $\mathrm{CO}_{2}$ Emissionen des öffentlichen Netzes fest, ob das Hybridfahrzeug oder das BEV geringere $\mathrm{CO}_{2}$ Emissionen hervorruft. Tabelle 7 aus Kapitel 11 zeigt, dass die $\mathrm{CO}_{2}$ Emissionen des BEV beim Nachladen über ein Gaskraftwerk vergleichbar mit dem dieselbetriebenen Hybridfahrzeug sind (fahrzyklusabhängig ist das BEV um $1 \%$ besser bis $4 \%$ schlechter). Bei Stein- oder Braunkohlebetrieb verursacht das BEV die doppelten bis dreifachen $\mathrm{CO}_{2}$ Emissionen (um $112 \%$ bis $172 \%$ mehr als das Hybridfahrzeug mit Fuel-Converter).

Das europäische Verbundnetz setzt bereits relativ viel $\mathrm{CO}_{2}$-arme Primärenergie ein (Kernenergie, Wind-, Wasser-, Solar-, Geo- und Abfallenergie). Der Rest sind Gas-, Stein- und Braunkohlekraftwerke [40]). Durch diesen Kraftwerksmix (Mittelwert 2013 - 2017) hat das BEV fahrzyklusabhängig um $5 \%$ bis $11 \%$ weniger $\mathrm{CO}_{2}$ Emissionen als das dieselbetriebene Hybridfahrzeug mit Fuel-Converter. Dies entspricht etwa dem gegenwärtigen Zustand. Wenn sich der generelle Elektrizitätsbedarf (IKT-Infrastruktur wie Rechenzentren, Mobilkommunikation, Blockchain-Technologie, etc.) und die Elektromobilität rascher entwickeln und damit der Bedarf an elektrischer Energie rascher zunimmt als die Umstellung der Stromnetze auf $\mathrm{CO}_{2}$ arme Primärenergie, müssen zur Ladung von BEV kalorische Kraftwerke einspringen, da der Großteil des Ausbaues der Wasser- und Solarkraftwerke bereits erfolgt ist und die bis 2030 weiter ausgebaute Windenergie vorwiegend die fehlende Energie der abgeschalteten Kernkraftwerke kompensieren muss [40] und [44]. Für Österreich bedeutet dies wegen der Stellung als Stromimporteur, dass jede zusätzlich verbrauchte kWh Strom importiert werden muss und man einen sogenannten „Verdrängungsmix“, der bis zu $800 \mathrm{~g} \mathrm{CO}_{2}$-eq/kWh betragen kann, erwartet, weil Kohlekraftwerke Gaskraftwerke vom Markt verdrängen. Damit wäre der 
$\mathrm{CO}_{2}$ Vorteil von BEV im europäischen Verbundnetz gegenüber Hybridfahrzeugen mit FuelConverter wieder verspielt.

Als Resümee kann festgehalten werden, dass Hybridfahrzeuge mit hohem Wirkungsgrad, also mit einem Fuel-Converter und Power-Tank, bis zur Umstellung der Stromerzeugung auf vorwiegend $\mathrm{CO}_{2}$ freie Primärenergie DIE Lösung für eine Verringerung der verkehrsbedingten $\mathrm{CO}_{2}$ Emissionen außerhalb von Ballungsräumen sind. Zusätzlich gewinnt die Volkswirtschaft Zeit und Mittel für die Schaffung einer flächendeckenden Schnellladeinfrastruktur für BEV oder Wasserstoff, da weiterhin auf das bestehende Tankstellennetz mit flüssigen Kraftstoffen zurückgegriffen werden kann.

\section{Danksagung}

Der Autor dankt den Mitarbeitern des Institutes für Elektrische Meßtechnik und Meßsignalverarbeitung der Technischen Universität Graz für die hilfreichen Diskussionsbeiträge zur Publikation. Mein besonderer Dank gilt Herrn Dr. Bernhard Schweighofer für die Durchführung der Simulationen zum Energieverbrauch von Fahrzeugen bei den in der Publikation gezeigten Fahrzyklen.

\section{Literatur}

[1] Messwerte eines Mercedes Benz E 200.

[2] Primary Battery Chemistries, http://www.epectec.com/batteries/chemistry/, access 10.1.2018.

[3] Albufera Energy Storage, Aluminium-Ion cells, https://www.albuferaenergystorage.com/index.php/aluminio-carbono/?lang=en, access 24.3.2019.

[4] Albufera Energy Storage, Aluminium-Sulfur cells, SALBAGE Project: https://www.salbageproject.eu/salbage-project/, access 24.3.2019.

[5] Fraunhofer-Institut für System und Innovationsforschung ISI, Energiespeicher-Roadmap (Update 2017) Hochenergie-Batterien 2030+ und Perspektiven zukünftiger Batterietechnologien, Karlsruhe, Dezember 2017, access 10.1.2018, http://www.isi.fraunhofer.de/isiwAssets/docs/t/de/publikationen/Energiespeicher-Roadmap-Dezember-2017.pdf.

[6] Mohamed Alamgir, Lithium has transformed vehicle technology, IEEE Electrification Magazine, Vol 5-1, pp 43-52, 7.3.2017. http://ieeexplore.ieee.org/stamp/stamp.jsp?tp=\&arnumber=7873398.

[7] Kokam_Cell_Brochure, Ultra high energy NMC Cell SLBP080085270, http://kokam.com/data/Kokam Cell Brochure V.4.pdf?PHPSESSID=075964321b2636ec87c0b31bf1592762, access 24.3.2019.

[8] GWL Power, Test cell results, http://gwl-power.tumblr.com/tagged/LTO, access 24.3.2019.

[9] Altairnano. 70Ah cell secifications, http://www.altairnano.com/products/70-amp-hour-cell/, access 24.3.2019.

[10] Toshiba, Toshiba rechargeable battery $\mathrm{SCiB}^{\mathrm{TM}}$ brochure, http://www.scib.jp/en/download/Toshiba RechargeableBattery-en.pdf and http://www.scib.jp/en/product/cell.htm, access 24.3.2019.

[11] Ecomeno.de-Das Elektroauto- \& E-Mobilitäts-Portal, Elektroauto Tesla Model S: Das steckt drin, https://ecomento.de/2016/03/14/elektroauto-limousine-tesla-model-s-das-steckt-drininfografik/, access 24.3.2019.

[12] https://www.elumeen.com/media/wysiwyg/produits/Elumeen panasonic NCR-18650B en.pdf, access 24.3.2019.

[13] Teslarati, Tesla Model S Weight Distribution, https://www.teslarati.com/tesla-model-s-weight/, access 31.12.2019.

[14] https://avt.inl.gov/sites/default/files/pdf/fsev/fact2015kiasoulev.pdf, Source 7.1.2018.

[15] Sonderforschungsbereich rwth-Aachen: Dieselmotor, http://www.sfb224.rwthaachen.de/Kapitel/kap4 4.htm, Abb. 4.4.2-4, access 10.1.2018. 
[16] autogenau.de, Brennraumtemperatur, http://www.autogenau.de/ratgeber/autolexikon/autolexikon-b/brennraumtemperatur.html, access 10.1.2018.

[17] G. Merker, R Teichmann, Hrsg, „Grundlagen Verbrennungsmotore“, ATZ/MTZ Fachbuch, Springer Verlag, 7. Auflage 2014, S. 161-162.

[18] http://www.uni-magdeburg.de/isut/TV/Download/Kapitel 10 Verbrennung WS0910.pdf, access 10.1.2018.

[19] Christoph Bernd König, "Das Potential der Dampfkühlung bei Gasturbinen und Kombianlagen" Diplomarbeit TU Wien 2002, https://publik.tuwien.ac.at/files/pub-mb 371.pdf, access 1.1.2020.

[20] http://www.bine.info/fileadmin/content/Publikationen/Basis Energie/Basis Energie Nr. 17/Ba sisEnergie 17 internetx.pdf, access 24.3.2019.

[21] HA technology now available at industry-first 64 percent efficiency, GE Power, 4. Dezember 2017. https://www.genewsroom.com/press-releases/ha-technology-now-available-industryfirst-64-percent-efficiency, access 24.3.2019.

[22] SDSN and FEEM, 2019 Roadmap to 2050: A Manual for Nations to Decarbonize by Mid-Century, Sep.2019, https://roadmap2050.report/static/files/roadmap-to-2050.pdf, access 27.11.2019.

[23] Springer Professional, Pkw-Antriebe im Überblick - Vergangenheit, Gegenwart und Zukunft, https://www.springerprofessional.de/motorentechnik/pkw-antriebe-im-ueberblickvergangenheit-gegenwart-und-zukunft/6561052, access 10.1.2018.

[24] Basshuysen, R. und Schäfer F., HRSG., Handbuch Verbrennungsmotor: Grundlagen, Komponenten, Systeme, Perspektiven. 7. aktualisierte und erw. Aufl., Springer Vieweg, 2015, S. 22.

[25] Toshihiro HIRAI, Nissan Motor Co., Ltd., Kanagawa, Japan, Strategic Future: Powertrain Vision for Tomorrow. In Proceedings 38. Intl. Motorensymposium, Wien, 27.-28. April 2017.

[26] energie-experte.org; https://www.energieexperten.org/heizung/brennstoffzelle/brennstoffzellen-typen/sofc-brennstoffzelle.html, access 24.3.2019.

[27] M. Klell, H. Eichlseder, A. Trattner, Wasserstoff in der Fahrzeugtechnik: Erzeugung, Speicherung, Anwendung, 4.Auflage, Springer Vieweg, 2018, Tab. 6.3.

[28] Autosieger.de, BMW Turbo Steamer: BMW Group nutzt Kraft-Wärme-Kopplung im Auto, http://www.autosieger.de/print.php?sid=8165, access 8.12.2005.

https://www.autosieger.de/bmw-group-nutzt-kraft-waerme-kopplung-im-autoarticle8165.html, access 20.3.2019.

[29] Heat2power SARL, Paris, Heat to power conversion benchmark, http://www.heat2power.net/en benchmark.php, access 16.6.2009.

[30] St. Hausberger, M. Schmitzberger, Umweltbundesamt, Emissionsverhalten von SUV - Sport Utility Vehicles, FVT Report, REP-0155, Wien, 2008.

[31] VDA, "Worldwide harmonized Light vehicles Test Procedure WLTP, https://www.vda.de/de/themen/umwelt-und-klima/WLTP-realitaetsnaehere-Ergebnisse-beimKraftstoffverbrauch/WLTP-Wieso-ein-neues-Testverfahren.html, access 1.1.2020.

[32] Peter Schöggl, AVL List GmbH, Die neue Formel 1-Technische Innovationen und Serienrelevanz, ÖVK-Vortrag TU Graz, 4.10.2017.

[33] G. Merker, R Teichmann, Hrsg, "Grundlagen Verbrennungsmotore“, ATZ/MTZ Fachbuch, Springer Verlag, 7. Auflage 2014, S. 430-435.

[34] Roland Schmetz, Überschlägige Berechnung der Verluste in elektrisch serienhybriden Antriebssträngen. In Proceedings 5. Fachtagung Hybride und energieeffiziente Antriebe für mobile Arbeitsmaschinen, 25.2.2015, KIT Scientific Publishing, Karlsruhe, S.150-151.

[35] Hannes Wegleiter, Energy Storage Systems for Automotive Applications, Habilitationsschrift an der TU Graz, April 2016, S. 157.

[36] All About Batteries, Part 12: Lithium Titanate (LTO), https://www.eetimes.com/author.asp?section id=36\&doc id=1325358\#, access 23.3.2019. 
[37] GKN Hybrid Power Gyrodrive Flywheel Schwungradenergiespeichersystem, http://www.gkngroup.com/gkn-cti/technology-andsolutions/future/Documents/Flywheel\%20Mk6\%20de.pdf, access 4.2.2018.

[38] Appendix C of the "Energy Information Administration/Household Vehicles Energy Use: latest data \& trends, the GREET Model", access 5.6.2009.

[39] Prof. St. Hausberger, ZU Graz, Artemis-CADC Test Messergebnisse Pkw, 19.3.2018

[40] Martin Beermann et-al, Treibausgasemissionen der Stromerzeugung und Transportdienstleistung von E-Fahrzeugen in Österreich, Symposium Energieinnovation, Graz, 16.2.2012, https://www.tugraz.at/fileadmin/user upload/Events/Eninnov2012/files/pr/PR Beermann 2.pdf, access 20.3.2018.

[41] Paul Scherrer Institut, Treibhausgasemissionen der zukünftigen europäischen Stromerzeugung, Bern, 2002: http://www.iaea.org/inis/collection/NCLCollectionStore/ Public/43/006/43006752.pdf, Seite 22, access 31.3.18.

[42] Amt der Vorarlberger Landesregierung, Energie- und Monitoringbericht Vorarlberg 2017, https://www.vorarlberg.at/pdf/eav monitoringbericht2017.pdf, access 2.4.2018.

[43] RWE, CO2 Emissionen der Stromerzeugung, BKE Bd. 59 (2007) Nr.10, https://m.vdi.de/fileadmin/vdi de/redakteur dateien/geu dateien/FB4/CO2missionen\%20der\%20Stromerzeugung 01.pdf, access 26.3.2018.

[44] Elektrotechnikblog, Das Phantom Strom: Wieviel C02 Emissionen entstehen beim Verbrauch von einer kWh Strom? https://elektrotechnikblog.at/das-phantom-strom-wieviel-c02-emissionenentstehen-beim-verbrauch-von-einer-kwh-strom/, access 3.4.2018.

[45] Helms, H. et al: Weiterentwicklung und vertiefte Analyse der Umweltbilanz von Elektrofahrzeugen. Umweltbundesamt D, Texte 27/2016. https://www.umweltbundesamt.de/sites/default/files/medien/378/publikationen/texte $27 \quad 20$ 16 umweltbilanz von elektrofahrzeugen.pdf, access 24.3.2019, Seite 164.

[46] Icha, P. und G. Kuhs (2017). Entwicklung der spezifischen Kohlendioxid-Emissionen des deutschen Strommix in den Jahren 1990 bis 2016. Dessau Roßlau Umwelt Bundesamt D. https://www.umweltbundesamt.de/sites/default/files/medien/1410/publikationen/2017-0522 climate-change 15-2017 strommix.pdf, access 7.9.2018, Seite 21.

[47] Umweltbundesamt A, Berechnung von Treibhausgas (THG)-Emissionen verschiedener Energieträger, August 2018, http://www5.umweltbundesamt.at/emas/co2mon/co2mon.html, access 30.9.2018

[48]Moro, A., Transportation Research Part D (2017), http://dx.doi.org/10.1016/j.trd.2017.07.012, access 1.10.2018.

[49] Thinkstep AG, Greenhouse Gas Intensity of Natural Gas, 5.5.2017, http://gasnam.es/wpcontent/uploads/2017/11/NGVA-thinkstep GHG Intensity of NG Final Report v1.0.pdf, access 1.10.2018.

[50] IEA, Electricity generation by source, Europe 1990-2017, https://www.iea.org/regions/europe, access 1.1.2020.

[51] INRIX Global Traffic Scorecard, INRIX Research Graham Cookson, Februar 2018, https://www.rbb24.de/panorama/beitrag/2018/02/berlin-verkehr-stau-traffic-scorecard-inrix2017.file.html/180206\%20Traffic\%20Scorecard.pdf, access 1.1.2020.

[52] KIT, DI J. Kunkelmann, Untersuchung des Brandverhaltens von Lithium-lonen- und LithiumMetall-Batterien in verschiedenen Anwendungen und Ableitung einsatztaktischer Empfehlungen, Brandschutzforschung der Bundesländer, Forschungsbericht 175, Dez. 2016, https://www.ffb.kit.edu/download/IMK\%20Ber.\%20Nr.\%20175\%20Kunkelmann\%20Lithium-Ionen\%20und\%20Lithium-Metall-Batterien\%20-\%20Ueberarbeitung\%20-\%2003.02.2017\%20-\%202.pdf, access 1.1.2020.

[53] ATG Kraftstofftanks und Zubehör, https://www.atg-germany.de/kraftstofftanks-und-zubehoer/, access 1.1.2020. 